Anuario da Facultade de Dereito da Universidade da Coruña

Vol. 22 (2018), pp. 21-53

ISSNe: 2530-6324 || ISSN: 1138-039X

DOI: https://doi.org/10.17979/afdudc.2018.22.0.5003

\title{
LA POSICIÓN JURÍDICA DE LA MUJER CON RELACIÓN A LOS DELITOS DE RAPTO, ESTUPRO, VIOLACIÓN Y ADULTERIO EN EL EDICTO DE TEODORICO
}

\author{
LUCÍA BERNAD SEGARRA \\ Profa. Titular Facultad de Derecho \\ Universitat de València
}

Resumen: La presente investigación trata de exponer la importancia que puede tener el estudio del Edictum Theodorici, para comprender la evolución del Derecho Romano y el alcance de su aplicación en la práctica de la Italia ostrogoda del s. VI. En este caso, nuestro estudio se centra en el análisis de la regulación de los delitos de rapto, estupro, violación y adulterio, especialmente en la situación jurídica de la mujer con relación a ellos.

Palabras clave: mujer, Derecho Romano, Edicto de Teodorico, rapto, estupro, violación, adulterio

Abstract: This research tries to expose the importance the Edictum Theodoricistudy, to understand the evolution of Roman Law and the scope of its implementation in practice of the Ostrogothic Italy in the 6th century. We have focussed on the legal situation of women in the regulation of abduction, statutory rape, rape and adultery. 
Keywords: woman, Roman Law, Edict of Theodoric, abduction, statutory rape, rape, adultery

SUMARIO: I. INTRODUCCIÓN. II. SOBRE EL EDICTO DE TEODORICO III. RAPTO IV. ESTUPRO Y VIOLACIÓN. V. ADULTERIO VI. CONCLUSIONES VII. BIBLIOGRAFÍA

\section{INTRODUCCIÓN}

En nuestra opinión, el estudio de toda institución jurídica ha de hacerse partiendo del concepto del Derecho como producto histórico, pues sólo podemos llegar a entender cómo es en un momento concreto tras el análisis de su evolución. ${ }^{1}$

El Derecho no puede entenderse desligado de la sociedad a la que va dirigido y sin tener en cuenta los elementos que lo conforman, como son la legislación, la jurisprudencia y la práctica jurídica. Para todo ello nos resulta especialmente importante el análisis de las fuentes de las que el legislador puede haber tomado la base jurídica para, en ocasiones, seguirlas $\mathrm{y}$, en otras, apartarse de ella $\mathrm{y}$, con ello, dar entrada a una regulación más cercana a las necesidades que exige la vida diaria. ${ }^{2}$

El origen de la presente investigación se encuentra en un trabajo anterior sobre la situación del colono en el Edicto de Teodorico ${ }^{3}$, pues fue en ese momento cuando nos llamó la atención el hecho de que, siendo un cuerpo legal no muy amplio, dedicara varios de sus fragmentos a la regulación de algunas cuestiones relativas a delitos que, por su naturaleza, atañen especialmente a la mujer, como son el rapto, el estupro, la violación y el adulterio.

El objetivo del presente trabajo es el de reflexionar sobre la concepción jurídica de estos delitos en la época del Edicto, a tenor de la regulación que de los mismos encontramos en dicho cuerpo legal, así como sobre la posición jurídica de la mujer con respecto a ellos. Para ello, el método que hemos seguido es el de localizar aquellos fragmentos en

\footnotetext{
${ }^{1}$ Así lo expresa con gran claridad FERNÁNDEZ DE BUJÁN, A, en Derecho Romano, (Madrid, 2017), pág. 30: "El derecho como producto histórico, en constante proceso de revisión y de crítica, se conforma sobre la base de un sustrato de conceptos, instituciones, clasificaciones, soluciones y lenguaje que, en buena medida, perviven desde su elaboración por el pensamiento jurídico romano hasta la actualidad"

${ }^{2}$ LAFFERTY, S., Law and Society in the Age of Theodoric the great. A Study of the Edictum Theoderici, (Cambridge, 2013), pág. 61, enumera las fuentes de las que el legislador se sirvió para la redacción del Edicto: extractos de los comentarios y opininones de los juristas Paulo, Ulpiano y Papiniano, los códigos Gregoriano y Hermogeniano, las Pauli sententiae el código Teodosiano y algunas leyes post-teodosianas.

3 BERNAD SEGARRA, L., "La situación jurídica del colonus en el Edicto de Teodorico", Revista General de Derecho Romano, 29, 2017, págs. 1-36. Es por ello que en el presente trabajo nos ocupamos de tres fragmentos $(21,63$ y 64) que tomamos del trabajo sobre el colono, puesto que fue al hacer la exégesis de los mismos cuando encontramos esas primeras referencias a la regulación de delitos que afectaban a las mujeres, por lo que entendemos que su análisis también debía aparecer aquí.
} 
los que se regula algún aspecto relacionado con los delitos de rapto, estupro, violación y adulterio en el cuerpo legal teodoriciano. Una vez localizados estos fragmentos, hemos procedido a su análisis pormenorizado, con la intención de obtener una correcta comprensión de los mismos. Con posterioridad a este análisis individualizado de cada disposición, los hemos agrupado por materias, puesto que, de este modo, podemos hacernos una idea sobre la regulación que el Edicto articula a propósito de estos delitos.

La utilización de esta metodología es lo que determina la propia estructura del trabajo, por lo que, después de la explicación de algunas cuestiones previas a propósito de la datación, autoría y ámbito de aplicación del Edicto, nos ocupamos del estudio de cada uno de los grupos de los diferentes fragmentos, buscando la conexión entre ellos, así como la existencia de un posible precedente romano o, por el contrario, la no existencia de éste, lo cual nos lleva a preguntarnos sobre los motivos de la regulación en cada caso.

Con todo ello, pretendemos dar una visión, lo más completa posible, sobre cuál es la concepción de dichos comportamientos delictivos, qué intereses pretende proteger el legislador en estos supuestos en los que la víctima es una mujer y, por último, tratar de averiguar en qué aspectos se sigue el antecedente romano y en qué otros el legislador teodoriciano se aparta de él para introducir alguna novedad.

\section{SOBRE EL EDICTO DE TEODORICO}

Entendemos que, como paso previo a nuestra investigación, es conveniente al menos apuntar algunas cuestiones relativas al Edicto, más aún teniendo en cuenta las dudas que suscita entre la doctrina la propia cuestión de su datación y de la autoría del mismo, sin más pretensión que poner en conocimiento del lector tales cuestiones, puesto que cualquier otra intención excedería la finalidad de este trabajo ${ }^{4}$.

En 1579 Pithou $^{5}$ publica el contenido del Edicto, y es a partir de esta publicación que se plantean dudas sobre dos cuestiones: por una parte, la atribución de la autoría de la compilación a Teodorico el Amalo, rey de los ostrogodos o a Teodorico II $^{6}$, rey de los visigodos y, por otra, la fecha de publicación, puesto que en la edición de Pithou esta no aparece.

\footnotetext{
${ }^{4}$ Exponemos aquí, de forma resumida, cuestiones que ya tratamos en el apartado 2 de nuestro trabajo anterior sobre el Edicto de Teodorico, "La situación..." cit., págs. 3 y ss., con la intención de que el lector del presente artículo tenga, al menos, conocimiento de ellas.

${ }^{5}$ Quien atribuye la autoría al rey de los ostrogodos Teodorico el Grande.

${ }^{6}$ En este sentido puede verse VISMARA, G.," Edictum Theodorici", Scritti di storia giuridica 1, Milano, 1987, pags. 12 y ss., donde el autor expone los diferentes argumentos sobre los que distintos autores sustentan una u otra teoría. También podemos consultar las diferentes posturas de unos y otros con abundante bibliografía en: RASI, P. "Ancora sulla paternità del Edictum Theodorici”, Annali di storia dil diritto 5/6, 1961-1962, págs. 113-136. Más recientemente: LAFFERTY, S. ”Law... ”cit., págs. 23 y ss.
} 
Patetta $^{7}$ señala que la opinión dominante habría fijado como fecha más probable la del año 500, sin embargo otra corriente, a la que él se adhiere, entiende que la fecha podría ser la del año $512^{8}$, o incluso en un periodo temporal que se extendería del año 500 al $524^{9}$.

En cuanto al contenido, se trata de un cuerpo legislativo de tan sólo 154 fragmentos que, en la mayoría de los casos, trata de forma muy breve algunas cuestiones que, por una razón u otra, el legislador consideró debían ser reguladas de forma expresa.

Pensamos que aquello de lo que el Edicto no se ocupaba, debía de tener una regulación que se mantenía en vigor, pues se aceptaba su validez en ese momento. De manera que el legislador se centra en aquellas cuestiones que requieren de una nueva regulación o alguna modificación respecto a la ya existente, con la finalidad de adaptarlo a las exigencias de la práctica. También se regulan supuestos en los que se sigue la regulación ya existente, que suele ser la romana ${ }^{10}$, pero de las que se ocupa, probablemente, porque se trata de cuestiones especialmente relevantes en ese momento.

En nuestra opinión, se trata de una legislación con una clara finalidad práctica, consecuencia de la situación que Teodorico debió de encontrarse, con graves supuestos de incumplimiento de la legislación vigente, así como conflictos específicos que requerían de una nueva regulación o de una modificación de la ya existente. Es por ello que, tanto en el prólogo ${ }^{11}$ como en el epílogo, ${ }^{12}$ el legislador pone de manifiesto que la

7 Sull'Anno della promulgacione dell'Editto di Teodorico, (Torino, 1893), págs. 3 y ss., donde cita y explica los argumentos sobre los que dichos autores se basan para llegar a tal conclusión.

${ }^{8}$ Ver sus argumentos en Sull'Anno...cit., pág. 8 y ss. VISMARA, G., “Edictum...”cit., pág. 13 y ss, expone las diferentes propuestas en cuanto a la datación en la doctrina.

${ }^{9}$ VISMARA, G., “Edictum...”cit., pág. 20.

${ }^{10}$ FERNÁNDEZ DE BUjÁN, A., Derecho Público Romano, 20 a ed., (Madrid, 2017), en pág. 227, señala que la recepción de Derecho Romano se muestra "de modo especial en las leyes visigodas, ostrogodas y burgundias” y sigue afirmando cómo “... aun aquellas reglas que más claramente llevan huella germánica están formuladas usualmente en técnica jurídica y en fraseología de Derecho vulgar, y no sólo porque estas leyes fueran escritas en latín, sino también porque el lenguaje germánico de la época no había desarrollado todavía una adecuada terminología". BARNWELL, P., "Emperors, Jurists and Kings: Law and Custom in the Late roman and Early Medieval west", Past and Present a journal of historical studies, 168, 2000, pág. 10, pone de relieve el hecho de que los pueblos bárbaros ya antes de asentarse dentro del Imperio romano, vivían cerca de las fronteras del mismo, lo cual supuso un contacto con el derecho romano así como también con el propio estilo de vida romano, es decir, sus costumbres, y cuando comienzan a codificar sus propias leyes, ya llevan años bajo dicha influencia. Sobre cómo se produce el asentamiento de los ostrogodos en territorio itálico, y su relación posterior con los habitantes de dicho territorio, puede verse, entre otros: AA. VV. (Ed. GOETZ, JARNUT, POHL), Regna and Gentes. The relationship between late Antique and early medieval peoples and kingdoms in the transformation of the roman world, (Leiden, 2003), HEATHER, P., "Gens and regnum among ostrogoths", págs. 107 y ss.; también: HEATHER, P., Goths and romans, (Oxford, 1991), págs. 332 y ss.; AMORY, P., People and identity in Ostrogothic Italy, (Cambridge, 1997) págs. 489 y ss.

11 “....:ut salva iuris publici reverentia et legibus omnibus cunctorum devotione servandis, quae barbari Romanique sequi debeant super expressis articulis, edictis praesentibus evidenter cognoscant."

12 "haec quantum occupationes nostrae admittere, vel quae nobis ad praesens occurrere potuerunt, cunctis tam barbaris, quam Romanis, sumus profutura complexi: quae omnium barbarorum, sive Romanorum debet servare devotio." 
finalidad del Edicto es dotar de regulación a conflictos que en ese momento y en ese lugar lo requieren y que dicha regulación es aplicable a toda la población, es decir, a romanos y ostrogodos.

\section{RAPTO}

El cuerpo legislativo de Teodorico dedica cinco fragmentos a la regulación del delito de rapto, de los que cuatro se refieren al supuesto en que la víctima es una ingenua y uno al caso en que la víctima es una esclava o colona, puesto que se trata de sujetos con diferente consideración jurídica. Como cuestión previa hemos de precisar que el rapto es un acto delictivo que supone la sustracción por la fuerza de una mujer, bien con la finalidad de contraer matrimonio con la raptada o la de su violación, por lo que en este último caso concurren dos actos delictivos, por una parte el rapto, que supone la sustracción por la fuerza del sujeto pasivo del lugar donde se encuentra, y, por otro la violación, que supone la imposición del acto sexual por la fuerza y siempre sin consentimiento del sujeto pasivo.

Una vez localizados los fragmentos pertinentes, procedemos a la exégesis y estudio de dichos textos para, con ello, llegar a entender las motivaciones de dicha regulación, así como cuál es el interés jurídico a proteger en este caso. Como ya vimos en nuestro trabajo anterior sobre este cuerpo legislativo, el legislador no se limita a seguir el derecho romano aún vigente, sino que, en ocasiones, como consecuencia de las necesidades que le impone la práctica, lo sigue con algunas modificaciones o adaptaciones y, en otras ocasiones se aparta de la regulación romana por no adaptarse a la realidad del territorio ostrogodo del siglo VI.

La regulación del rapto en el Edicto se inicia con el fragmento 17:

De raptore ingenuae mulieris aut virginis.

Raptorem ingenuae muleris aut virginis, cum suis complicibus vel ministris, rebus probatis iuxta legem iubemus extingui, et si consenserit rapta raptori, pariter occidatur.

En este fragmento se establece que, de acuerdo con lo dispuesto por la ley, los raptores de una mujer ingenua o virgen, junto con sus cómplices o colaboradores ${ }^{13}$, sean ejecutados una vez probados los hechos, y si la raptada consiente el rapto, igualmente sea ejecutada ${ }^{14}$.

${ }^{13}$ PULIATTI, S., en "La dicotomía vir-mulier e la disciplina del ratto nelle fonti legislative tardoimperiali", SDHI, 61, 1995, pág. 473, al señalar los sujetos activos que intervienen en el delito de rapto distingue, en materia de cómplices, entre los cómplices que intervienen en persona en la irrupción domiciliaria, los cómplices que no intervienen directamente pero que ayudan, por ejemplo, dando refugio al autor, utilizando las fuentes en ambos casos la palabra participes, y el caso de los ejecutores de condición servil que prestan su servicio en la comisión del delito, siendo estos últimos a quienes haría referencia el término ministri que aparece en este texto del que nos estamos ocupando.

14 Respecto a la pena impuesta, señala PULIATTI, S. "La dicotomia... ”cit., pág.474: "la pena inicialmente discende dall'inquadramento del ratto quale crimen vis entro l'ambito della Lex Iulia de vi; 
La iuxta lege a la que se hace referencia en el texto es una constitución del emperador Constantino de fecha incierta ${ }^{15}$, pero que suele datarse en el año 326 , recogida en CTh.9.24.1 ${ }^{16}$, en la que el emperador establece toda una regulación sobre el rapto, que determina un cambio en la naturaleza jurídica del delito, pues deja de pertenecer al ámbito familiar para pasar a ser una ofensa pública $(\text { crimina })^{17}$. Con dicha constitución se da paso a la distinción entre el rapto con fines sexuales y el rapto cuya finalidad es el matrimonio $^{18}$. En nuestra opinión, probablemente, la finalidad de la constitución de

ma non si può stabilire con esattezza quale essa fosse da principio. Le leges Iuliae: de vi publica e de vi privata originariamente prevedevano sanzioni patrimoniali ed esilio perpetuo. In seguito, paralelamente all'affermarsi del ratto quale figura criminosa autonoma, fu introdotta la pena di morte." Señala el mismo autor cómo la referencia al ultimum supplicium ya aparecía en el siglo I. Con posterioridad, encontramos una referencia expresa a dicha pena en un texto de Marciano, D. 48, 6, 5, 2: Qui vacantem mulierem rapuit vel nuptam, ultimo supplicio punitur et, si pater iniuriam suam precibus exoratus remiserit, tamen extraneus sine quinquenii praescriptione reum postulare poterit, cum raptus crimen legis Iuliae de adulteriis potestatem excedit.

${ }^{15}$ Sobre las diferentes propuestas a propósito de la datación de dicha constitución, ver PULIATTI, S., "La dicotomía..." cit., pág. 482, n. 33.

${ }^{16}$ CTh. 9. 24. De raptu virginum vel viduarum. Imp. Constantinus a. ad populum. Si quis nihil cum parentibus puellae ante depectus invitam eam rapuerit vel volentem abduxerit, patrocinium ex eius responsione sperans, quam propter vitium levitatis et sexus mobilitatem atque consilii a postulationibus et testimoniis omnibusque rebus iudiciariis antiqui penitus arcuerunt, nihil ei secundum ius vetus prosit puellae responsio, sed ipsa puella potius societate criminis obligetur. 1. Et quoniam parentum saepe custodiae nutricum fabulis et pravis suasionibus deluduntur, his primum, quarum detestabile ministerium fuisse arguitur redemptique* discursus, poena immineat, ut eis meatus oris et faucium, qui nefaria hortamenta protulerit, liquentis plumbi ingestione claudatur. 2. Et si voluntatis assensio detegitur in virgine, eadem, qua raptor, severitate plectatur, quum neque his impunitas praestanda sit, quae rapiuntur invitae, quum et domi se usque ad coniunctionis diem servare potuerint et, si fores raptoris frangerentur audacia, vicinorum opem clamoribus quaerere seque omnibus tueri conatibus. sed his poenam leviorem imponimus solamque eis parentum negari successionem praecipimus. 3. Raptor autem indubitate convictus si appellare voluerit, minime audiatur.4. Si quis vero servus raptus facinus dissimulatione praeteritum aut pactione transmissum detulerit in publicum, Latinitate donetur, aut, si Latinus sit, civis fiat Romanus: parentibus, quorum maxime vindicta intererat, si patientiam praebuerint ac dolorem compresserint, deportatione plectendis. 5. Participes etiam et ministros raptoris citra discretionem sexus eadem poena praecipimus subiugari, et si quis inter haec ministeria servilis condicionis fuerit deprehensus, citra sexus discretionem eum concremari iubemus. Dat. kal. april. Aquileia, Constantino a. VI. et Constantino c. coss.

${ }^{17}$ BERNAD, L., "La situación...” cit., pág. 9.

${ }^{18}$ Modalidad ésta de rapto de la que nos habla Marciano en D. 48, 6, 5, 2: Qui vacantem mulierem rapuit, vel nuptam, ultimo supplicio punitur; etsi pater inniuriam suam precibus exoratus remiserit, tamen extraneus sine quinquennii praescriptione reum posturare poterit, quum raptus crimen legis Iuliae de adulteriis potestatem excedit. En el texto se nos habla del supuesto de rapto de mujer, se supone que ingenua, tanto casada como no, estableciendo en ambos casos la pena de muerte para el raptor. A continuación, contempla el jurista el supuesto en el que el padre de la mujer raptada perdonase al raptor. Es interesante la expresión que utiliza: "etsi pater iniuriam suam precibus exoratus remiserit", puesto que se nos dice que el padre perdona la injuria por él sufrida. Esto es así puesto que se entiende que el interés jurídico a proteger, en el caso de delito de rapto, es el honor del padre y el de toda la familia, y no sólo el de la mujer. Aunque este perdón por parte del padre no impide que otra persona, pueda presentar tal demanda contra el raptor, sin posibilidad de que la presentación de tal demanda pueda prescribir, puesto que, de forma expresa, se nos dice que dicho delito queda fuera del ámbito de la Lex Iulia de adulteriis, con lo que no se le aplica la prescripción dentro del periodo de cinco años que establece dicha ley para la persecución del delito de adulterio. 
Constantino fuera regular una situación que se está dando en la práctica, que es el matrimonio por rapto ${ }^{19}$, en el sentido de evitar que sea visto como una alternativa al matrimonio convencional; y ello es lo que justificaría la gravedad de las penas ${ }^{20}$ para todos aquellos que, de un modo u otro, intervienen en el rapto, incluida la raptada. Con ello se pretende acabarcon este tipo de actos como alternativa al matrimonio. También hay que tener en cuenta que esta constitución es una más dentro del grupo de constituciones promulgadas por Constantino dirigidas a los ámbitos familiar y social, ${ }^{21}$ a fin de adecuarlos a la concepción que de los mismos tiene el propio emperador, y en las que ya se deja ver algunas ideas cuyo origen se encuentra en el ideario cristiano ${ }^{22}$. Seguramente esta es la razón por la que la constitución citada será la base sobre la que Justiniano legislará sobre el delito de rapto en el 533, aunque incluyendo los supuestos de rapto de ingenuas y el de esclavas o libertas ${ }^{23}$.

\footnotetext{
${ }^{19}$ El rapto puede cometerse con fines matrimoniales, ya sin consentimiento de la mujer ya con su consentimiento, pero siempre supone un uso de la fuerza en su comisión y en esta constitución se sancionan tanto uno como otro. Esta posibilidad del rapto con consentimiento de la mujer es uno de los elementos que lo separa de la violación, puesto que éste es un acto que se realiza siempre por la fuerza y sin el consentimiento de la mujer, tal y como señala RODRÍGUEZ ORTIZ, V. en Historia de la violación. Su regulación jurídica hasta fines de la edad media, (Madrid, 1997), págs. 126 y ss. Con anterioridad a la regulación de Constantino el rapto aparece regulado en la Lex Iulia de iudiciis privatis, de época de Augusto, aproximadamente del año 17 a C., coincidiendo con la promulgación de la Lex Iulia de iudiciis publicis, por lo que suelen citarse bajo una misma denominación, Leges Iuliae de iudiciis privatis et publicis, tal y como señala FERNÁNDEZ DE BUJÁN, A. en "Reformas legislativas de Augusto", Revista General de derecho romano, 23, 2014, pág. 7. Con carácter general, sobre estas leyes puede verse: GIRARD, P.F., "Les leges Iuliae iudiciorum publicorum et privatorum", ZSS, 34, 1923; QUERZOLI, S. "La puella rapta: paradigmi retorici e apprendimento del diritto nelle Istituzioni di Elio Marciano", Annali Online Lettere, vol. 1-2, 2011, pág. 157, señala sobre el origen de la regulación del rapto: "Ė possibilie che all'origine della trattazione del ratto di una donna- secondo regole che si ripetono costantemente nelle fonti retoriche, almeno fino al II secolo d.C.- fossero disposizioni normative dei diritti greci, purtroppo non tutte rintracciabili con sicurezza. Nella legislazione attica, rimangono tracce di una norma che costringeva il rapitore a sposare la ragazza che aveva violentato qualora si rifiutasse di pagare l'ammenda prevista."
}

${ }^{20}$ PULIATTI, S., “La dicotomía...”cit., pág. 493, recoge cuál es el sistema de penas que establece Constantino con relación al rapto, así como la dureza de las mismas: " a) rapitore: morte atroce (presumibilmente rogo o condanna ad bestias); b) puella volens: morte atroce, come il rapitore; c) vittima invita, ma poi disponibile: morte atroce, come il rapitore; d) vittima invita ma insuficientemente resistente: esclusione dalla successione paterna e materna; e) nutrice: morte per soffocamento da colata di piombo fuso in gola; $\mathrm{f}$ ) participes e ministri liberi: deportazione (ma inicialmente rogo); g) ministri schiavi: vivicombustione; h) genitori remittenti: deportazione." El mismo autor, a partir de este sistema de penas, concluye que Constantino al distribuir de tal manera las penas tiene en cuenta los dos parámetros vir-mulier y liberi-servi, de manera que la pena va a cambiar según el status de los sujetos y no según su sexo, de modo que ante la comisión del mismo delito el tratamiento de hombre y mujer es el mismo.

${ }^{21}$ GEOFFREY, N., The family in late antiquity: The rise of christianity and the endurance of tradition, (Leiden, Boston 2002), en pág. 72 afirma: "Constantine was the first emperor since Augustus to legislate so broadly and so extensively on the family in particular and social issues more generally." Con toda esta nueva regulación, Constantino modifica la regulación legislativa establecida por Augusto en estas cuestiones.

${ }^{22}$ PASTOR DE AROZENA, B., "Retórica imperial: el rapto en la legislación de Constantino", Faventia, 20/1, 1998, pág. 80.

${ }^{23}$ C. 9. 13. 1. Imperator Justinianus. Raptores virginum honestarum vel ingenuarum, sive iam desponsatae fuerint sive non, vel quarumlibet viduarum feminarum, licet libertinae vel servae alienae 
sint, pessima criminum peccantes capitis supplicio plectendos decernimus, et maxime si deo fuerint virgines vel viduae dedicatae ( quod non solum ad iniuriam hominum, sed ad ipsius omnipotentis dei inreverentiam committitur, maxime cum virginitas vel castitas corrupta restitui non potest): et merito mortis damnantur supplicio, cum nec ab homicidii crimine huiusmodi raptores sint vacui.

1. Ne igitur sine vindicta talis crescat insania, sancimus perhanc generalem constitutionem, ut hi, qui huiusmodi crimen commiserint et qui eis auxilium tempore invasionis praebuerint, ubi inventi fuerint in ipsa rapina et adhuc flagrante crimine comprehensi a parentibus virginum vel viduarum vel ingenuarum vel quarumlibet feminarum aut earum consanguineis aut tutoribus vel curatoribus vel patronis vel dominis, convicti interficiantur.1a. Quae multo magis contra eos obtinere sancimus, qui nuptas mulieres ausi sunt rapere, quia duplici crimine tenentur tam adulterii quam rapinae et oportet acerbius adulterii crimen ex hac adiectione puniri.1b. Quibus connumerabimus etiam eum, qui saltem sponsam suam per vim rapere ausus fuerit.1c. Sin autem post commissum tam detestabile crimen aut potentatu raptor se defendere aut fuga evadere potuerit, in hac quidem regia urbe tam viri excelsi praefecti praetorio quam vir gloriosissimus praefectus urbis, in provinciis autem tam viri eminentissimi praefecti praetorio per Illyricum et Africam quam magistri militum per diversas nostri orbis regiones nec non viri spectabiles praefectus Aegypti vel comes Orientis et vicarii et proconsules et nihilo minus omnes viri spectabiles duces et viri clarissimi rectores provinciarum nec non alii cuiuslibet ordinis iudices, qui in locis inventi fuerint, simile studium cum magna sollicitudine adhibeant, ut eos possint comprehendere et comprehensos in tali crimine post legitimas et iuri cognitas probationes sine fori praescriptione durissimis poenis adficiant et mortis condemnent supplicio.1d. Quibus et, si appellare voluerint, nullam damus licentiam secundum antiquae constantinianae legis definitionem.1e. Et si quidem ancillae vel libertinae sint quae rapinam passae sunt, raptores tantummodo supra dicta poena plectentur, substantiis eorum nullam deminutionem passuris. If. Sin autem in ingenuam personam tale facinus perpetretur, etiam omnes res mobiles seu immobiles et se moventes tam raptorum quam etiam eorum, qui eis auxilium praebuerint, ad dominium raptarum mulierum liberarum transferantur providentia iudicum et cura parentum earum vel maritorum vel tutorum seu curatorum. $1 \mathrm{~g}$. Et si non nuptae mulieres alii cuilibet praeter raptorem legitime coniungentur, in dotem liberarum mulierum easdem res vel quantas ex his voluerint procedere, sive maritum nolentes accipere in sua pudicitia remanere voluerint, pleno dominio eis sancimus applicari, nemine iudice vel alia quacumque persona haec audente contemnere.

2. Nec sit facultas raptae virgini vel viduae vel cuilibet mulieri raptorem suum sibi maritum exposcere, sed cui parentes voluerint excepto raptore, eam legitimo copulent matrimonio, quoniam nullo modo nullo tempore datur a nostra serenitate licentia eis consentire, qui hostili more in nostra re publica matrimonium student sibi coniungere. Oportet etenim, ut, quicumque uxorem ducere voluerit sive ingenuam sive libertinam, secundum nostras leges et antiquam consuetudinem parentes vel alios quos decet petat et cum eorum voluntate fiat legitimum coniugium

3. Poenas autem quas praediximus, id est mortis et bonorum amissionis, non tantum adversus raptores, sed etiam contra eos qui hos comitati in ipsa invasione et rapina fuerint constituimus.3a. Ceteros autem omnes, qui conscii et ministri huiusmodi criminis reperti et convicti fuerint vel eos susceperint vel quacumque opem eis intulerint, sive masculi sive feminae sunt, cuiuscumque condicionis vel gradus vel dignitatis, poenae tantummodo capitali subicimus, ut huic poenae omnes subiaceant, sive volentibus sive nolentibus virginibus seu aliis mulieribus tale facinus fuerit perpetratum. 3 b. Si enim ipsi raptores metu atrocitatis poenae ab huiusmodi facinore temptaverint se, nulli mulieri sive volenti sive nolenti peccandi locus relinquetur, quia hoc ipsum velle mulieri ab insidiis nequissimi hominis qui meditatur rapinam inducitur. Nisi etenim eam sollicitaverit, nisi odiosis artibus circumvenerit, non facit eam velle in tantum dedecus sese prodere.3c. Parentibus, quorum maxime vindicta intererat, si patientiam praebuerint ac dolorem remiserint, deportatione plectendis.4. Et si quis inter haec ministeria servilis condicionis fuerit deprehensus, citra sexus discretionem eum concremari iubemus, cum hoc etiam Constantiniana lege recte fuerat prospectum.5. Omnibus legis Iuliae capitulis, quae de raptu virginum vel viduarum seu sanctimonialium sive antiquis legum libris sive in sacris constitutionibus posita sunt, de cetero abolitis, ut haec tantummodo lex in hoc capite pro omnibus sufficiat.6. Quae de sanctimonialibus etiam virginibus et viduis locum habere sancimus. Iust. a Hermogeni mag. off.(a.533). 
Volviendo al fragmento 17 del Edicto, vemos en él varias circunstancias que suscitan nuestro interés, como son:

- El sujeto pasivo del delito es la mujer ingenua o la mujer virgen. Con relación a tal cuestión, vemos cómo en esto difiere con respecto a la fuente más directa de la que bebe la disposición, la ya citada constitución de Constantino, en la que se refiere a lo largo de la misma sólo al supuesto del rapto de la mujer virgen, puella, sujeta a la potestad del pater, sin hacer referencia expresa a ningún otro supuesto.

- La fijación de la pena, que consiste en la ejecución del raptor, de sus cómplices o colaboradores, así como de la propia mujer en el caso de que ésta hubiese consentido. Esta aplicación de la pena de muerte tanto para el raptor como para la raptada que consiente se encuentra también en la constitución de Constantino, donde aparece por primera vez, parece que con la intención de endurecer la sanción penal por la comisión del delito de rapto.

Recordemos que el rapto se puede producir sin o con el consentimiento de la mujer y que en este último caso, en la mayoría de los supuestos, la finalidad del rapto es la del matrimonio, por lo que es claro que también en la legislación teodoriciana se prohíbe tal matrimonio, tal y como ocurría en la legislación constantiniana.

Comprobamos cómo la pena para tal delito es la más grave, la ejecución del autor del delito así como de sus cómplices y colaboradores, incluso la de la raptada si ésta consintió. En la constitución de Constantino no se señala de forma expresa la pena por la comisión del delito de rapto, aunque ésta era la pena máxima ${ }^{24}$, que no puede entenderse de otro modo más que la muerte del condenado. Sobre esta cuestión, señala Puliatti ${ }^{25}$ que, en origen, la pena sería una sanción patrimonial o el exilio perpétuo, pues estas son las penas previstas por las Leges Iuliae de vi publica y de vi privata, y más tarde, cuando el rapto ya se configura como un crimen autónomo, su sanción pasa a ser la pena de muerte ${ }^{26}$.

- El texto habla de complicibus vel ministris, a los que se les aplicará la misma pena que al autor del rapto. Esta referencia a cómplices y colaboradores también la encontramos en el antecedente legal romano del fragmento, por lo que entendemos hay que precisar a quiénes se está refiriendo con uno y otro término. En CTh. 9, 24, 1, $5^{27}$ se señala que participes y ministriserán sometidos a la misma pena que el raptor.

En este sentido Puliatti, ${ }^{28}$ al explicar quiénes son los sujetos activos que intervienen en el delito de rapto distingue, en materia de cómplices, entre los cómplices que

\footnotetext{
${ }^{24}$ Summum suplicium, como señala EVANS GRUBBS, J., "Abduction marriage in antiquity: A Law of Constantine (CTh IX.24.I) and Its Social Context”. The Journal of Roman Studies, vol. 79,1989, pág. 66.

25 "La dicotomía...” cit., pág. 475.

${ }^{26}$ Así aparece ya como la pena habitual en estos casos en el texto de Marciano contenido en D. 48, 6, 5,2 (ver texto en nota 16)

${ }^{27}$ Participes etiam et ministros raptoris citra discretionem sexus eadem poena praecipimus subiugari, et si quis inter haec ministeria servilis condicionis* fuerit deprehensus, citra sexus discretionem eum concremari iubemus

28 "La dicotomía...", cit., pág. 473.
} 
intervienen en persona en la irrupción domiciliaria, los cómplices que no intervienen directamente pero que ayudan, por ejemplo, dando refugio al autor, utilizando las fuentes en ambos casos la palabra participes, y el caso de los ejecutores de condición servil que prestan su servicio en la comisión del delito, siendo estos últimos a quienes haría referencia el término ministri.

Al comparar el contenido del fragmento 17, donde se regula el rapto de mujer virgen, con la regulación contenida en la constitución de Constantino observamos que el primero sigue al segundo pero no en su totalidad, pues, siguiendo en ello a lo señalado por Lafferty ${ }^{29}$, observamos que hay algunas cuestiones que el legislador teodoriciano obvia en el fragmento.

- En primer lugar, en la constitución se establece que el consentimiento de esta mujer virgen al matrimonio con su raptor no tiene consecuencias legales, al igual que su testimonio en un juicio era inválido. Nada de ello se señala en el fragmento 17 , al igual que ocurre con la pena de privación del derecho a heredar de sus padres a aquellas que aunque no consintieron en el rapto, no hicieron lo suficiente para alertar del mismo.

- Otra cuestión que ignora el legislador teodoriciano es la del supuesto del rapto con complicidad de la nodriza o cuidadora de la virgen raptada, a la que en la legislación de Constantino se castiga, por haber convencido a la joven para ser raptada. Sobre este olvido, compartimos la justificación que propone Lafferty ${ }^{30}$, quien entiende que ello no puede ser más que, de nuevo, una consecuencia de la finalidad eminentemente práctica del Edicto, de modo que, atendiendo a la realidad del entorno del territorio al que va a aplicarse, es bien cierto que no muchas serían las familias que en un ambiente mayoritariamente rural, podrían permitirse tener una nodriza al cuidado de la formación y educación de sus hijas.

El Código de Teodorico continúa la regulación del rapto con el siguiente fragmento:

Fr. 18. De Parente raptae, aut curatore eius.

Si parentes raptae aut curator eius, quae minore aetate rapta est, exsequi et vindicare talis facti culpam forte neglexerit, pactum, quod non licet de hoc crimine faciendo, poenam patiantur exilii

En este caso, se nos dice que el pariente o el guardián de la menor de edad raptada que renuncia a perseguir y demandar al culpable, tras un pacto ilícito con relación a dicho crimen, sufrirán la pena de exilio. El término utilizado, parentes, incluye tanto al padre como a la madre, y a ambos se les condena a la misma pena, la del exilio, sin que exista, en este caso diferenciación o gradación en la pena por razón de sexo, tal y como ocurría en la constitución de Constantino, en la que, de forma expresa, se hace hincapié en el hecho de que la pena es la misma sea cual sea el sexo del sujeto ${ }^{31}$.

\footnotetext{
${ }^{29}$ Law..., cit., pág. 184.

${ }^{30}$ Law..., cit., pág. 181.

${ }^{31}$ Tal y como señala PULIATTI, S., "La dicotomia...", cit. pág. 491, a la hora de graduar las penas la constitución de Constantino lo hace en base a la dicotomía liberi-servi, y no a la dicotomía vir-mulier. Un ejemplo de ello sería el caso de los cómplices, supuesto en el que se distingue el caso de losparticipes
} 
Se trata, por tanto, en este supuesto, de sancionar la conducta de aquellos padres o aquel curador que acuerdan con el raptor renunciar a presentar una demanda en su contra, pues con tal actitud lo que se consigue, en la práctica, es dar por válida la unión entre raptor y raptada. En estos casos, la legislación teodoriciana es clara al igual que lo era la constitución de Constantino ${ }^{32}$, en el sentido de no consentir tal conducta y establecer en ambos casos la pena del exilio. Esta obligación por parte de los padres de la raptada de ejercitar la demanda procesal en los casos de rapto, se encuadra también en el grupo de modificaciones que introduce Constantino, puesto que en la legislación anterior a éste no parece que existiera tal obligación ${ }^{33}$.

Nos llama la atención que en el fragmento del Edicto se mencione expresamente el caso de la menor de edad y del curador, referencias que no aparecen en la constitución de Constantino, en el que sólo se menciona el caso de los padres.

La regulación teodoriciana continúa con el siguiente fragmento:

Fr. 19. De servo, qui querelam de raptu viderit dissimulari.

Servus vero, si querelam de raptu dissimulari a dominis et pactione crimen senserit definiri atque iudiciis prodiderit, libertate donetur.

En este caso, el legislador se ocupa del supuesto en el que un esclavo descubre que ha sido ocultada por sus dueños la denuncia del rapto y se establece que en el caso de que lo ponga en conocimiento del juez, sea puesto en libertad.

Esta referencia al esclavo que delata a sus dueños aparece tanto en el Edicto como en la Constitución de Constantino ${ }^{34}$, lo que para Lafferty ${ }^{35}$ supone una manifestación de la especial relevancia que supone el delito para la sociedad en ambos casos, puesto que, en definitiva, supone otorgar el mayor premio, la libertad, a aquellos que traicionan la confianza de sus dueños, primando la represión y sanción del delito por rapto. No se puede tolerar que aquellos cuyo honor ha sido mancillado, puesto que no podemos olvidar que con dicho delito no sólo se atenta contra el honor de la raptada, sino también el de toda la familia, no lo persigan procesalmente. Supone pues una excepción al tratamiento del delator que encontramos en el propio Edicto en el frg. 35

El Edicto dedica un fragmento al caso del delator.

Frg. 35. De delatoribus.

yministri libres, aquienes se castiga con ladeportación, y a los ministri esclavos, a quienes se condena a ser quemados.

${ }^{32}$ CTh. 9, 24, 1, 4 Si quis vero servus raptus facinus dissimulatione praeteritum aut pactione transmissum detulerit in publicum, Latinitate donetur, aut, si Latinus sit, civis fiat Romanus: parentibus, quorum maxime vindicta intererat, si patientiam praebuerint ac dolorem compresserint, deportatione plectendis.

${ }^{33}$ No aparece mención alguna a tal obligación, por ejemplo, en el ya citado texto de Marciano D. 48, 6, 5, 2.

${ }^{34}$ CTh. 9, 24, 1, 4. Si quis vero servus raptus facinus dissimulatione praeteritum aut pactione transmissum detulerit in publicum, Latinitate donetur, aut, si Latinus sit, civis fiat Romanus: parentibus, quorum maxime vindicta intererat, si patientiam praebuerint ac dolorem compresserint, deportatione plectendis.

${ }^{35}$ Law ..., cit., pág. 183. 
Is qui quasi sub specie utilitatis publicae, ut sic necessarie faciat, delator existit, quem tamen nos execrari omnino profitemur, quamvis vel vera dicens, legibus prohibeatur audiri; tamen si ea, quae ad aures publicas detulerit, inter acta constitutus non potuerit adprobare, fammis debet absumi.

En este caso el legislador señala en el fragmento que la ley establece que el delator no debe ser oído en juicio y si acusa a alguien sin aportar hechos que demuestren tal acusación, será quemado.

El contenido de dicho fragmento está en consonancia con una constitución de Constantino del año $313^{36}$, en la que se establece dicha prohibición con carácter general y la pena capital para el delator.

Es evidente pues que, para el legislador ostrogodo reviste una especial gravedad la comisión del delito de rapto, y tan es así, que admite una excepción con relación a un delito también especialmente grave como es la delación de un esclavo con respecto a sus dueños. En este caso, el legislador se encuentra con que tiene que elegir entre sancionar uno u otro delito. Resulta claro que entiende que el delito más grave o más importante es el de rapto. En nuestra opinión, ello es una consecuencia del hecho de que, con la comisión del delito de rapto, se produce una ofensa no sólo al honor de la mujer raptada, sino también al honor de la propia familia.

El legislador teodoriciano continúa ocupándose del delito de rapto en.

Fr. 20. De raptu intra quae tempora concludatur.

Raptum intra quinquennium liceat omnibus accusare, post quinquennium vero nullus de hoc crimine faciat quaestionem, etiam si intra supra scriptum tempus egisse aliquid de legibus doceatur: maxime cum et filii de hoc matrimonio suscepti exacto quinquenio legitimorum et iure et privilegio minantur.

En este fragmento el legislador señala el tiempo en el que el delito de rapto debe ser procesado, estableciendo para ello un plazo de cinco años para poder presentar una acusación por este crimen; no pudiendo ser iniciada investigación alguna transcurrido dicho plazo, incluso si se demuestra que una reclamación legal pudo haber sido interpuesta dentro de ese plazo de tiempo, sobre todo cuando los hijos de este matrimonio, pasados estos cinco años, cuentan con la legitimación por derecho y por privilegio.

Podemos señalar que el plazo de cinco años no se aplicaba en la época en que el rapto no contaba con una regulación específica ${ }^{37}$ y estaba sancionado por la Lex Iulia de vi

\footnotetext{
${ }^{36}$ CTh.10.10.1. Imp. Constantinus a. ad populum. Post alia: de delatoribus iam certa statuimus; quibus si quis contra fecerit, poenam capitalem excipiet. Proposita XV kal. feb. Constantino a. III et Licinio III conss. (313 ian. 18).

${ }^{37}$ Sobre la prescripción de los delitos en derecho romano, hay que señalar que es comúnmente admitido por la doctrina que tal idea es ajena, en sus orígines, a dicho ordenamiento, y que no será hasta el dominado cuando comienza a utilizarse tal concepto, en concreto, lo encontramos en una constitución de los emperadores Diocleciano y Maximiano del año 293, C. 9, 22, 12: querella fasi temporalibus
} 
publica $^{38}$ y tampoco aparece mencionado en la constitución de Constantino, pero sí en una constitución anterior, de los emperadores Valentiniano I, Valente y Graciano en el año $374^{39}$, por título: Quninquenii praescriptione in crimine raptus, en la que se establece un plazo de cinco años, a partir de la comisión del delito, para que cualquiera pueda presentar demanda por rapto, después de establecer que la demanda por dicho delito puede ser presentada por cualquiera.

En definitiva, la consecuencia de esta disposición es que a partir del transcurso de este plazo de tiempo fijado por la ley, el matrimonio contraído por rapto deviene inatacable desde el punto de vista procesal y los hijos, si los hubiere, consolidan sus derechos y su legitimación.

La fijación de un plazo de tiempo limitado para la prescripción del delito de rapto cuya finalidad es el matrimonio, seguramente tiene su fundamento en la idea de que si dicha unión originada por rapto continúa existiendo transcurridos cinco años, es de suponer que se trata de una unión estable y con vocación de permanecer en el tiempo, ello además podría darse junto con la circunstancia de que de dicho matrimonio hubiera habido descendencia, cuya legitimidad ya no puede atacarse transcurrido dicho período de tiempo.

Nos parece interesante señalar que en la legislación de Constantino ${ }^{40}$ se priva al raptor condenado de la posibilidad de apelar, cuando, tal y como señala Lafferty ${ }^{41}$, en la legislación imperial la apelación es considerada como una garantía contra la corrupción judicial que pudiera darse a nivel local.

Esta prohibición de apelar aplicable al raptor condenado, no aparece en la legislación teodoriciana, por lo que cabe preguntarse si no se menciona porque sigue vigente la regulación constantiniana o porque no existe tal limitación.

Por lo visto hasta ahora, podemos pensar que el legislador teodoriciano conoce el contenido de la constitución y toma de ella aquello que entiende es aplicable a la realidad del territorio ostrogodo, lo cual nos puede llevar a concluir que si expresamente no recoge dicha mención a la prohibición de apelar en estos casos, ello obedece a su

praescriptionibus non excluditur, nisi viginti annorum exceptione, sicut cetera quique fere crimina. Si bien algunos autores entienden que dicha referencia al plazo de prescripción es obra de los compiladores justinianeos, como es el caso de VOLTERRA, "Intorno alla prescrizione dei reati in diritto romano", BIDR, 37, 1929, págs. 57 y ss.

${ }^{38}$ LAFFERTY, S., Law...cit., pág. 183, n. 109.

${ }^{39} \mathrm{CTh}$ 9, 24 ,3. Imppp. Valens, Gratianus et Valentinianus aaa. ad Maximinum pf. p. Qui coniugium raptus scelere contractum voluerit accusare, sive propriae familiae dedecus eum moverit seu commune odium delictorum, inter ipsa statim exordia insignem recenti flagitio vexet audaciam. Sed si quo casu quis vel accusationem differat vel reatum, et opprimi e vestigio atrociter commissa nequiverint, ad persecutionem criminis ex die sceleris admissi quinquennii tribuimus facultatem. quo sine metu interpellationis et complemento accusationis exacto, nulli deinceps copia patebit arguendi, nec de coniugio aut sobole disputandi. Dat. XVIII. kal. dec. Gratiano a. III. et Equitio coss.

${ }^{40} \mathrm{CTh}$ 9, 24, 1, 3. Raptor autem indubitate convictus si appellare voluerit, minime audiatur.

${ }^{41}$ Law..., cit., pág. 32: "Such rules demonstrate that the right of appeal was considered by imperial legislators as an essential tool for limiting perceived instances of judicial corruption or misconduct at the local level." 
voluntad de no reconocer tal excepción. Una prueba de ello puede ser el hecho de que en el Edicto se trate la cuestión de la apelación, concretamente en el fragmento $55,{ }^{42}$ en el que se establece, como principio general, la obligación del juez de conocer de las apelaciones que se le presenten y las medidas a tomar en aquellos supuestos en los que no se pueda presentar la apelación por causa de la ausencia del juez. Es decir, el legislador asume el principio que reconoce el derecho de todo condenado a apelar, que ya es claramente reconocido en la legislación imperial romana anterior, y de forma deliberada, deja de lado la excepción establecida por Constantino para el caso del raptor condenado. Ello, en nuestra opinión,puede entenderse como un reconocimiento en el Edicto del derecho a apelar por parte del raptor condenado.

De la regulación del Rapto de colona se ocupa el fragmento:

\section{Fr. 21. Si ancillam alienam aut originariam congregata multitudine} rapiat.

Si quis ancillam alienam aut originariam violenter cum multitudine congregata rapuerit, si ingenuus est, raptoris poena feriatur, quia violentiae crimen admittit: si servus est aut colonus et sua hoc tantum voluntate commisit, simili ratione puniatur. ${ }^{43}$

En este caso el texto señala que, si alguien raptase a una esclava o una colona con violencia en multitud reunida, si es ingenuo, se le imponga la pena de rapto, ya que ha admitido el crimen de violencia: si es siervo o colono, y esto en tanto que lo comete por su propia voluntad, por la misma razón sea castigado.

El análisis de cualquier texto antiguo, sea literario o sea jurídico, exige para su interpretación un acercamiento al estudio pormenorizado de su terminología. En el caso de este texto nos encontramos con algunos términos que nos suscitan dudas que entendemos puede tener también el lector, dudas agravadas por el hecho de que se trata de un texto romano-barbárico y puede que algún térnino tenga un significado distinto al originario, por lo que pasamos a analizarlos de forma individualizada.

Originaria: El recurrente término originaria hace referencia a los colonos, de tal manera que en la constitución se expresa ancillam alienam, por un lado, y originariam,

\footnotetext{
${ }^{42}$ Omnes appellationes iudicem debere suscipere. Omnes appellationes suscipiant ii provinciarum iudices, a quibus provocari potest: quando optimae conscientiae conveniat etiam superfluam appellationem sine dubitatione suscipere, dum de appellationis merito sacer posssit perpensis legibus cognitor iudicare. Quod si iudex suam absentiam procuravit, ne appellatorios libellos accipiat: in locis celeberrimis, qui appellare voluerit, libellum de absentia iudicis et de sua appellatione exhibere debere censemus. Iudex autem, qui aut suscipere appellationem contempserit, aut certe in cuistodiam dederit, aut verberaverit, aut aliquo dispendio laeserit appellantem, decem librarum auri amissione feriatur, quas fisci compendiis cura sacri cognitoris praecipimus aggregari; officium quoque, cuius interest, mulctae legitimae subiacebit.

${ }^{43}$ Tomamos el análisis textual de nuestro trabajo anterior sobre el colono en el Edicto: "la Situación..." cit. pág 6 y ss.
} 
es decir, la colona, por otro ${ }^{44}$; una figura con una historia en auge desde Diocleciano y su reforma de las tasas ${ }^{45}$.

Multitudine congregata: Entiéndase como reunión o multitud reunida. En este caso, parece referirse al rapto llevado a cabo con la participación de varios, es decir, con un conjunto de personas que participan con el autor en la comisión del rapto. Y así lo entendemos, basándonos en los siguientes argumentos:

-Es una expresión que no encontramos en ninguna otra fuente, sea jurídica, sea literaria, que pueda aportarnos una información válida al respecto.Sólo la encontramos en el fragmento16 del Edicto ${ }^{46}$, en el que se regula el arrebato de una posesión ajena con violencia cum multitudine congregata.

-El autor del Edicto, conoce el contenido de la constitución de Constantino CTh.9.24.1 $\mathrm{y}$ en ella, in fine, se hace referencia expresa al supuesto de los cómplices y acompañantes del raptor - participes etiam et ministros raptoris-, lo cual nos lleva a pensar que la expresión cum multitudine congregatadel código teodoriciano, se debe interpretar en este sentido.

-Siguiendo esta estela lógica de pensamiento, en relación con la constitución de Constantino, creemos que la expresión cum multitudine congregata es una simplificación del redactor ostrogodo o de algún otro autor entre Constantino y Teodorico, por lo que el autor no se ha sentido en la necesidad de precisar entre los diversos tipos de participación.

-Un último aspecto a tener en cuenta es la calificación de la participación, es decir, si los consideramos cómplices o coautores, cosa que el legislador no parece distinguir y no le importa técnicamente, por lo que no parece hacer diferenciación respecto a la responsabilidad por razón del grado y tipo de participación en el delito.

Rapuerit: Termino asociado al delito cometido específicamente contra la mujer, lo que concreta el supuesto de hecho.

\footnotetext{
${ }^{44}$ CUENA, F., "Nuevos significados de origo en las fuentes legislativas postclásicas", Revista General de Derecho Romano, 10, 2008, pág.17. EIBACH, D., Untersuchen zum spätantiken Kolonat in der kaiserlichen Gesetzgebung, (Bonn, 1980), pág.213. COLLINET, P., "Le colonat dans 1'empire romain", en Recueils de la Societé Jean Bodin, 2, (Bruxelles, 1959), págs.95 y ss. DE MARTINO, F., Historia económica de la antigua Roma, (Trad. E. Benitez, Storia económica di Roma antica), (Madrid, 1985), pág.520.

${ }^{45}$ AA. VV. (ARNOLD, J., BJORNLIE, S., SESSA, K.), A Companion to Ostrogothic Italy, (Leiden, 2016, GREY, C., "Landowning and Labour in the Rural Economy", pág.278.

${ }^{46}$ De his, qui ad possessionem alienam violenter vadunt (violentus vadit). Qui ad possessionem alienam violentus advenerit cum multitudine congregata, si aut ipse aut aliquis ex eodem numero, casu, dum repellitur violentia, occisus fuerit, is qui per necessitatem hoc fecit, a metu poenae liber habeatur.
} 
Ingenuus: La traducción más lógica es la de libre por nacimiento ${ }^{47}$. Ello puede entenderse mejor a raíz de la literalidad de la disposición en la que se contrapone ingenuo a servus-colonus.

Visto el significado que los términos dudosos pueden plantear, pasamos a exponer el caso regulado de una forma un poco más integrativa; a saber, que el caso regula exclusivamente el rapto de una colona o de una esclava ajena con violencia y en compañía de otros; se trata un supuesto delictivo asociado específicamente a la mujer, cuando este acto se realiza con la participación de otros. Este acto puede realizarse distinguiendo, primero, si lo realiza un ingenuo, es decir, quien es libre por nacimiento, en cuyo caso se le impone la pena de rapto; segundo, si lo realiza el siervo o colono por su propia voluntad, en cuyo caso, por la misma razón será castigado.

En el caso del ingenuo, se nos dice de forma clara que se imponga la pena de rapto, la cual se justifica por la admisión del crimen con violencia. En el caso del siervo o colono se hace una especial mención a que el delito se comete por su propia voluntad, lo cual justifica el castigo.

La parte que a nosotros nos interesa es la relativa a la regulación de la colona y al colono en materia de rapto y que, desde el punto de vista legislativo, constituye una novedad del Edicto deTeodorico.

A propósito de este delito, resulta interesante una idea que traemos a colación, y que es planteada por Evans-Grubbs ${ }^{48}$. La autora afirma que este tipo de delito no se daría tanto

\footnotetext{
${ }^{47}$ En LEWIS- SHORT, A Latin Dictionary, (Oxford, 1879), encontramos la definición de ingenuus como "free born, born of free parents", siguiendo la ya enunciada en Gai I, 11: Ingenui sunt qui liberi nati sunt; libertini qui ex iusta servitute manumissi sunt.

${ }^{48}$ EVANS-GRUBBS, J., “Abduction...”cit., págs. 61 y ss. La autora enmarca la regulación que establece Constantino del rapto en el incremento de legislación de carácter general que se produce en la época y que lleva a que el emperador se ocupe de cuestiones que, con anterioridad, no han merecido una legislación específica, como es este caso, puesto que el rapto, probablemente, no se daría tanto entre la clase social urbana, a la que principalmente va dirigida la legislación clásica de la época del Principado, sino en remotas comunidades rurales. Según continua la autora, es el primer reconocimiento expreso del matrimonio por rapto (aunque en la práctica ya estaría reconocido con anterioridad). En una sociedad como la romana, los esponsales rara vez se rompen y si se hace es, o porque los padres de la novia rechazan al pretendiente, o porque se rompe el acuerdo y, en nuestra opinión, ello sería, en muchas ocasiones, la motivación para el rapto. En estos casos, el matrimonio con el raptor podría verse como la única salida para la mujer raptada. Incluso en determinadas situaciones el matrimonio por rapto puede ser una alternativa: cuando la familia de la novia no puede pagar la dote y cuando la familia del novio no puede pagar el banquete. La autora concluye que la voluntad del legislador de acabar con estas situaciones sería lo que explicaría la dureza de los castigos y lo que determinará que, a partir de la constitución de Constantino, el raptus ya no es un asunto de la familia, sino que pasa a ser una ofensa pública (crimina). DESANTI, L., "Costantino, Il ratto e il matrimonio riparatore”, SDHI, 52, 1986, pág. 197, señala, a propósito de la constitución de Constantino, que ésta tendría como uno de sus principales objetivos el endurecimiento de las penas. Sobre las motivaciones de Constantino al endurecer las penas en caso de rapto, algunos autores han visto en ello una influencia del pensamiento cristiano, que ya en esta época comienza a ser mayoritario, sin embargo, otros no consideran que dicha ifluencia sea determinante al menos en el caso del rapto. En este sentido, NGUYEN, N. L., "Roman rape: an overview of roman rape laws from the republican period to Justinian's reign", Michigan Journal of Gender and Law. Vol. 13, 1, 2006, pág. 110, afirma: "Here, the Christian view is dramatically different tan Constantine's view on abduction marriages, and thus it would be erroneous to conclude such a pure Christian basis in
} 
entre la clase social urbana sino en remotas comunidades rurales, ámbito al que pertenece el colonato, y ello, en nuestra opinión, justificaría que el legislador teodoriciano incluyese la mención expresa a colona y colono en la regulación del rapto.

El Edicto de Teodorico, que aparece con posterioridad a la promulgación de la ya citada constitución de Constantino a propósito de la regulación del matrimonio por rapto y con anterioridad a la promulgación de la Compilación de Justiniano, es el único de los tres cuerpos legales en el que aparece mencionado el colono.

De entre el conjunto de textos destaca el fragmento 21, pues es el único que hace referencia al rapto de la colona y al supuesto en el que dicho rapto haya sido cometido por un colono.

El hecho de que la colona, como víctima del rapto, y el colono, como posible causante de un rapto de sierva o de colona se regulen en el Edicto de Teodorico nos puede llevar a pensar que estamos ante una innovación teodoriciana para el caso del rapto y que quizás estemos ante un problema que se da sólo en esa zona y merece ser regulada, por la importancia que la fuerza de trabajo tiene en un ámbito mayoritariamente rural como es al que va dirigido el Edicto.Por tanto, en este caso encontramos, una vez más, una manifestación de esta voluntad del legislador de adaptar la legislación romana ya existente a su propia realidad. Un elemento a favor de esta teoría sería el hecho de que ya Constancio en una constitución del año 354, CTh 9,25,1 ${ }^{49}$, condena, presumiblemente a la muerte, a los que ofenden la castidad de aquellas que dedican su vida a Cristo, y también la compilación justinianea se ocupa del rapto de vírgenes y viudas dedicadas a Dios ${ }^{50}$, mientras que tal supuesto no aparece en el Edicto de Teodorico, lo cual es una muestra del hecho, más que probable, de que tal circunstancia no fuera común en el territorio, básicamente rural, al que va destinada la regulación ostrogoda $^{51}$. Otras conclusiones que se pueden extraer de la lectura del fragmento son, por una parte, la equiparación sierva-colona, sin que ello suponga una identificación, exactamente igual que ocurría en el Breviario de Alarico; y, por otra, la distinción entre si el ejecutor es un ingenuo o si es un siervo-colono. En este último caso, no se

Constantine's enactment of the raptus laws. Instead, a possibly more powerful motivation for Constantine's law would have been the control of public order that was threatened by raptus.

${ }^{49}$ CTh. 9, 25, 1, Imp. Constantius a. ad Orfitum... eadem utrumque raptorem severitas feriat, nec sit ulla discretio inter eum, qui pudorem virginum sacrosanctarum et castimoniam viduae labefactare scelerosa raptus acerbitate detegitur. Nec ullus sibi ex posteriore consensu valeat raptae blandiri. Dat. XI. kal. sept. Constantio a. VII. et Constante c. coss.

${ }^{50}$ C. 9, 13, 1. Raptores virginum honestarum, vel ingenuarum, sive iam desponsatae fuerint sive non, vel quarumlibet viduarum feminarum, licet libertinae vel servae alienae sint, pessima criminum peccantes, capitis supplicio plectendos decernimus; et maxime si Deo fuerint virgines vel viduae dedicatae (quod non solum ad iniuriam hominum, sed ad ipsius omnipotentis Dei irreverentiam committitur, maxime quum virginitas vel castitas corrupta restitui non possit), et merito mortis damnantur supplicio, quum nec ab homicidii crimine huiusmodi raptores sint vacui.

${ }^{51}$ LAFFERTY, S., Law...cit., pág. 185, en este sentido afirma: "The silence of the compilers concerning this specific type of raptus is suggestive of the fact taht sacrosanct virgins or widows were an uncommon feature of rural life in the Italian countryside at this time. Presumably, the hazards of the Italian countryside discouraged individuals from constructing female communities outside the large towns and cities, for all female monasteries were, by the end of the sixth century, located in urban centers of the peninsula." 
distingue si lo hace por voluntad propia o no.A este último supuesto, es decir, al caso en el que el rapto se cometa por voluntad de otro, hace referencia el texto siguiente:

\section{Fr. 22. De conductore conscio aut connivente.}

Si vero conscio conductore aut iubente aut connivente vel non prohibente hoc fecerit, etiam conductor ipse tamquam facti reus simili poena feriatur. Si autem domino sciente vel iubente hoc fecit, eandem possesssionem, de qua raptor egressus est, fisco profuturam dominus incunctanter amittat.

En este caso, se establece que si alguien comete dicho rapto con el conocimiento, la complicidad o el permiso del conductor, éste será castigado como si él hubiera cometido el crimen. Y si alguien perpetra este crimen con el conocimiento o incitación de un propietario, éste perderá inmediatamente, a beneficio del fisco, esta propiedad de la que el raptor ha huido.

En caso de que el siervo o colono cometan el rapto se les aplica la pena del ingenuo; la razón de que la pena sea la misma, pero se distinga en el supuesto de hecho, se entiende en relación al hecho de que sólo colono y siervo pueden cometer un delito contra su voluntad, obligados por el dominus, como consecuencia de la relación de sometimiento con respecto al mismo.

Sobre la posible justificación acerca de una necesaria regulación del rapto de colona, así como de sierva, apunta Lecce ${ }^{52}$, que en el reino ostrogodo se hizo necesario garantizar la productividad agrícola, lo que exigía garantizar, a su vez, la seguridad de la propiedad agraria que, en su opinión, estaba especialmente amenazada por la ocupación de fundos, casas, así como el robo de esclavos y animales. En este sentido, podemos entender que la colona pudiese ser objeto de rapto y necesitara de protección, dado que, en definitiva, y para esta época, el colonato es una imprescindible fuerza de trabajo en la explotación agrícola. A ello cabe sumar que los hijos siguen la condición de la madre y, por tanto, son nuevas fuerzas de trabajo; todo ello en una época de declive demográfico, lo cual nos puede llevar a pensar en un aumento del rapto a colonas y, en consecuencia, la necesidad de articular la protección y sanción legal frente a dicho rapto.

\section{ESTUPRO Y VIOLACIÓN}

El estupro y la violación aparecen tratados de forma conjunta por parte del legislador teodoriciano, circunstancia ésta lógica, por cuanto se trata de figuras afines ${ }^{53}$. En ambas figuras hay un yacimiento con otra persona, en el caso de la violación contra la voluntad del sujeto pasivo, por tanto con uso de la violencia o la fuerza y, en el caso del estupro,

\footnotetext{
${ }^{52}$ LECCE, M., "La vita económica de 1'Italia durante la dominazione dei goti nelle varie de Cassiodoro", Economia e Storia, 3, 1956, pág. 360.

${ }^{53}$ LAFFERTY, S., Law...cit., pág. 181, n. 103: "Roman law did not define rape per se, but sexual violence could be prosecuted as stuprum per vim (ilegal sexual intercourse by force), which was categorized under the Lex Iulia de vi publica.
} 
con consentimiento del sujeto pasivo, pero dicha conducta se entiende es delictiva precisamente por ser quién es el sujeto pasivo. Tan es así que encontramos un texto de Modestino en el que se precisa con qué sujetos se comete estupro al yacer con ellos mediando su consentimiento ${ }^{54}$, siendo éstos la viuda, la mujer virgen o un joven, puesto que el yacimiento consentido con mujer casada entraría dentro del tipo del delito de adulterio $^{55}$. Según se nos dice en un texto de Papiniano ${ }^{56}$, el estupro sin violencia y sobre personas libres estaría sancionado por la ley Iulia de adulteriis coercendiis.

Encontramos en el Edicto dos fragmentos en los que el legislador se ocupa del supuesto de estupro a la viuda:

\section{Fr. 61. Si matrona vidua cuiuslibet libidine corrumpatur.}

Si quis vero servus, etiamsi cum volente et adquiescente vidua hoc crimen admiserit, flammis ultricibus exuratur: illa quoque adulterii poena damnda, quae non erubuit servili subiacere libidini.

En este caso, el texto viene a decir que si un esclavo comete el delito de estupro, incluso contando con el consentimiento y la complicidad de la viuda, éste será quemado; la viuda también, pues a quien no avergüenza yacer con un esclavo, merece la misma pena de adulterio.

El sujeto pasivo en este caso es la viuda y el activo un esclavo, compartiendo ambos, en este caso, el mismo castigo, que no es otro que la pena de muerte. En el caso de la viuda que consiente en esta relación con el esclavo, se asimila su situación a la de la adúltera, por lo que se le aplica la misma pena. El estupro con la viuda, ya con el consentimiento de ésta ya sin él, va a suponer igual castigo para el esclavo, ser quemado vivo.

En este caso, es claro que el hecho del yacimiento voluntario, por parte de una persona con una especial consideración, como es la viuda, con un esclavo, reviste una especial gravedad, que deriva del ataque al honor de la familia de la mujer, consecuencia tanto de mantener relaciones sexuales, faltando a la especial honorabilidad que como viuda se le exige, como de tenerlas con un sujeto de tan baja condición social.

En el siguiente fragmento, continúa el legislador con el supuesto de las relaciones entre viuda y esclavo, reafirmando la idea formulada en el fragmento anterior según la cual, tanto si esa relación fue consentida o no, la pena para el esclavo es morir quemado. Aunque se introduce una novedad, que es el caso de la viuda calificada como "mujer vulgar".

\section{Fr. 62 Si matrona vidua volens corrumpatur a servo.}

\footnotetext{
${ }^{54}$ D. 48, 5, 34, 1 (Mod. Lib. Reg.): Adulterium in nupta admittitur, stuprum in vidua, vel virgine, vel puero committitur.

${ }^{55}$ D. 48, 5, 34, pr. (Mod. Lib. Reg.): Stuprum committit, qui liberam mulierem consuetudinis causa, non matrimonii continet, excepta videlicet concubina.

${ }^{56}$ D. 48, 5, 6, pr. (Pap. Lib. I de adulteriis): Inter liberas tantum personas adulterium stuprumve passas lex Iulia locum habet; quod autem ad servas pertinet, et legis Aquiliae actio facile tenebit, et iniuriarum quoque competit; nec erit deneganda praetoria quoque actio de servo corrupto; nec propter plures actiones parcendum erit in huiusmodi crimine reo.
} 
Si matrona vidua alicuius libidine volens corrupta sit, stuprum admittiut; nisi forte vilis vulgarisque sit mulier. Cum his enim viduis adquiescentibus si quis concubuerit, quas artis operam, aut ministerii laborem pulice exercere constiterit, hoc crimine nec ipse nec illae teneantur obnoxii.

Este fragmento se ocupa del supuesto en el que una matrona viuda es corrompida por un esclavo con su consentimiento, por lo que entraríamos aquí en el supuesto del estupro, a menos que se trate de una mujer vulgar, pues continua el texto afirmando que si alguien tiene relaciones con esas viudas que consienten y que son conocidas por la práctica de un servicio público, ni él ni ellas responderán por esta ofensa.

Nos parece interesante señalar que el texto utilice el término matrona viuda y no simplemente viuda. En nuestra opinión, con la elección de dicha expresión el legislador está señalando no a cualquier viuda, sino a la que fue matrona en el sentido que esta palabra tenía para los romanos y con la que se hacía referencia no a toda mujer casada, sino a mujeres casadas que gozan de una especial dignidad y rango ${ }^{57}$, siendo probable que sea esta especial dignidad de la que estaría revestida esta mujer lo que hace especialmente grave el comportamiento de esta viuda a la que se refiere el legislador. Este concepto es pues un concepto típicamente romano con el que se alude al ideal romano de virtud y castidad ${ }^{58}$, y que, por lo que parece, pervive en la sociedad a la que va dirigida el código Teodoriciano.

En este texto se tratan dos supuestos diferentes, el primero es el del yacimiento de la matrona que ha enviudado con esclavo, caso que el texto califica como estupro, pues se trata de una relación sin violencia, y el segundo es el del yacimiento entre esclavo y viuda que resulta ser una mujer vulgar ${ }^{59}$, quedando en este caso excluido el delito de estupro. Por cómo continúa el texto podemos entender que esta referencia a la vulgaridad de la mujer parece referirse al supuesto de que la viuda se dedique de forma pública a la prostitución ${ }^{60}$. De hecho, el texto continúa ya haciendo referencia expresa al supuesto del yacimiento con viudas que consienten y cuya práctica de la prostitución es conocida, de modo que en este caso, sea cual sea la condición del que yace con ellas, ni él ni ellas serán responsables. Dentro de este grupo de mujeres vulgares también

\footnotetext{
${ }^{57}$ Ver la entrada matrona en LEWIS-SHORT, A Latin Dictionary, Oxford 1879, donde se define como "a married woman, wife, matron", pero se nos explica el significado social que alcanza dicho término: "The word very early acquired the accessory idea of (moral or social) dignity, rank."

58 DIXON, J. E.; The Language of Roman Adultery. Tesis doctoral. University of Manchester, 2012, (www.escholar.manchester.ac.uk), pág. 30: "The figure of the matrona was central to the roman ideal of virtue and chastity. Draped in the stola she represented a modest and loyal mother and wife, who worked to preserve the dignity and lineage of her family. The purpose of such a figure was to produce children that would ensure the continuation of the family line and to manage the household.

${ }^{59}$ Sobre el significado de dicha expresión, ver GEORGES, K. E., Deutsch-Lateinisches Handworterbuch aus den quellen zusammengetragen und mit besonderes Bezugnahme auf Synonymik und Antiquitäten, mit Berücksichtigung der besten hulfsmittel, (Leipzig, 1961), pág. 1346: “mulier vulgaris: mulier, quae domum suam ómnium libidinibus patefecit; prostibulum"

${ }^{60}$ Ver, en el mismo sentido, una constitución del año 290 que encontramos en C. 9, 9, 22: Diocletianus et Maximianus aa. Oblimosi. Si ea, qua estupro tibi cognita est, passim venalem formam exhibuit, ac prostitutam meretricio more vulgo se praebuit, adulterii crimen in ea cessat.
} 
podemos incluir aquellas que regentan o trabajan en una taberna ${ }^{61} \mathrm{y}$, en todo caso podemos entender que dicha expresión es una referencia al ejercicio de la prostitución. ${ }^{62}$

En el resto de fragmentos que el Edicto dedica a la regulación del estupro, se refiere a supuestos de estupro con violencia que, en definitiva, constituyen un delito de violación, como ya hemos explicado.

Respecto a los antecedentes romanos en la regulación del delito de violación hay que señalar que, en origen, es muy probable que su sanción quedara en el ámbito de la violencia privada ${ }^{63}$ y que no fuera hasta su inclusión entre los delitos sancionados por la Lex Iulia de vis publica, que no comenzaran a perfilarse los elementos que constituirían el tipo penal sancionado ${ }^{64}$. Cuando se habla de violación en derecho romano se hace mención al supuesto en el que un hombre utiliza la fuerza y la violencia para forzar a una mujer o a un hombre contra su voluntad. Es fundamental que tal acto se realice sin consentimiento del sujeto pasivo, pues en caso contrario el delito no existe. En el caso de relaciones sexuales consentidas con una ingenua virgen o viuda, estaríamos ante un caso de estupro y en el supuesto de relaciones sexuales con una ingenua casada, ante un caso de adulterio. ${ }^{65}$

\footnotetext{
${ }^{61}$ HERREROS GONZÁLEZ, C.; "Las meretrices romanas: mujeres libres sin derechos", Iberia. Revista de la Antigüedad, 14, 2001, págs. 114 y ss. Si bien es cierto que el propio emperador Constantino, en CTh. 9, 7, 1, una constitución del año 326, establece una distinción entre estas mujeres: Imp. Constantinus a. Africano v. c. Quae adulterium commisit, utrum domina cauponae an ministra fuerit, requiri debebit, et ita obsequio famulata servili, ut plerumque ipsa intemperantiae vina praebuerit; $u t$, si domina tabernae fuerit, non sit a vinculis iuris excepta, si vero potantibus ministerium praebuit, pro vilitate eius, quae in reatum deducitur, accusatione exclusa, liberi, qui accusantur, abscedant, quum ab his feminis pudicitiae ratio requiratur, quae iuris nexibus detinentur, hae autem immunes a iudiciaria severitate praestentur, quas vilitas vitae dignas legum observatione non credidit. Dat. III. non. febr. Heracleae, Constantino a. VII. et Constantio c. coss.
}

En este caso, a propósito de qué mujeres cometen adulterio al mantener relaciones sexuales fuera del matrimonio, distingue el caso de las propietarias o las que regentan tabernas y las mujeres que trabajan en dichos establecimientos, de modo que las primeras cometen adulterio y las segundas no, debido a la condición de los servicios que pueden prestar en ellos.

${ }^{62}$ En tal sentido encontramos utilizada dicha expresión en varios textos, como, por ejemplo, ocurre en D. $48,5,13,2$, texto en el que Ulpiano afirma que no comete estupro aquel que yace con una mujer vulgar: sed et in ea uxore potest maritus adulterium vindicare, quae vulgaris fuerit, quamvis, si vidua eset, impune in ea stuprum committeretur. $\mathrm{Al}$ caso de la mujer que trabaja en una taberna, en el mismo sentido se refiere Paulo en Paul. Sent. 2, 26, 11: Cum his, quae publice mercibus vel tabernis exercendis procurant, adulterium fieri non placuit.

${ }^{63}$ RODRIGUEZ ORTIZ, V., Historia...cit., pág. 74, señala que, aunque en origen no estaría incluido el delito de violación en el delito de iniuria recogido en la Ley de las XII tablas, “...la interpretatio de los pontífices extendió al delito de violación la acción privada de injurias, y no sólo a la víctima del delito, sino también a sus familiares, fundamentalmente a sus padres y marido, en caso de estar casada."

${ }^{64}$ A ello se hace mención en un texto de Marciano recogido en D. 48, 6, 3, 4 (Inst. lib. IV): Praeterea punitur huius legis poena, qui puerum, vel feminam, vel quemquam per vim stupraverit. Texto en el que Marciano define el delito de violación como el estupro cometido con violencia a mujer u hombre, estableciendo que dicho delito está sancionado por la lex Iulia de vi publica.

65 Tal y como aparece expresado en una constitución de los emperadores Diocleciano y Maximiano, promulgada en el año 290 y recogida en C. 9, 9, 20: Foedissimam earum nequitiam, quae pudorem suum alienis libidinibus prosternunt, non etiam earum, quae per vim stupro compressae sut, irreprehensam 
Con la regulación y sanción penal del delito de violación, tanto en el derecho romano, como en el derecho ostrogodo, se pretende castigar la ofensa al honor y la integridad física de la agredida, pero también el honor de la familia a la que ésta pertenece, al igual que ocurría en el caso del delito de rapto, tal y como hemos visto en e apartado anterior.

El legislador teodoriciano, trata por separado los supuestos delictivos según la condición del sujeto pasivo, distinguiendo tres supuestos de violación: el de virgen ingenua, supuesto al que dedica dos fragmentos: el 59 para el caso en que el sujeto activo es un ingenuo y el 63 para el caso en que el sujeto activo es un esclavo o colono; el de la viuda, al que dedica el fr. 60 y el de la violación de esclava u originaria ajena, supuesto del que se ocupa el fragmento 64.

Respecto al sujeto pasivo de la violación, hay que señalar que en estos fragmentos, de los que vamos a pasar a ocuparnos, se habla sólo de la mujer virgen o viuda, sin que aparezca mención alguna al hombre como sujeto pasivo de la violación ${ }^{66}$, supuesto éste que sí estaba contemplado en los escritos de los juristas romanos, como es el caso de Marciano ${ }^{67}$ y Ulpiano. ${ }^{68}$

Pasamos a ocuparnos, en primer lugar, de la regulación para los casos de violación de virgen ingenua. En el fragmento 59 se regula tal supuesto en el caso de que el sujeto activo sea un ingenuo:

\section{Fr. 59. Qui ingenuam virginem per vim corruperit.}

Qui ingenuam virginem per vim corruperit, si idoneo patrimonio gratulatur, et est genere nobilis et eandem accipere cogatur uxorem; ita ut ei sponsalitiae titulo largitatis quintam partem patrimonii sui noverit conferendam. Quod si iam habens uxorem ista commiserit, tertiam partem patrimonio sui illi, quam per vim corruperit, sub idonea et solemni scriptura dare cogatur; ut illa quae per eum iacturam pudoris incurrit, honestum possit invenire coniugium. Si autem nullo patrimonio aut nobilitate fulcitur oppressor et violator pudoris ingenui, suplicio adficiatur extremo.

En este caso, se nos dice que aquél que ha corrompido a una virgen con violencia, tratándose de un individuo con patrimonio y noble, será compelido a tomarla como esposa, entendiendo que una quinta parte de dicho patrimonio se confiere a la mujer en concepto de dote. Si dichos actos los ha cometido estando casado, está obligado a entregar una tercera parte de su patrimonio a la corrompida, en idónea y solemne

voluntatem leges ulciscuntur. Quin etiam inviolatae existimationis ese, nec nuptias earum aliis interdici, merito placuit.

66 Lo mismo ocurre en la legislación visigoda, tal y como señala RODRÍGUEZ ORTIZ, V., Historia ...cit., pág. 189.

${ }^{67}$ D. 48, 6, 3, 4 (Marc. Lib 14. Insti.): Praeterea punitur huius legis poena, qui puerum, vel feminam, vel quemquam per vim stupraverit.

${ }^{68}$ D. 48,6, 6 (Ulp. lib VII, de off. Procons.): Et eum, qui puerum ingenuum rapuit, puniendum Divus Pius rescripsit in haec verba: "Exemplum libelli dati mihi a Domitio Silvano, nomine Domitti Silvani patrui, subiici iussi, motus querela eius, qua significavit, filium suum ingenuum iuvenem admodum raptum atque conclusum, mox verberibus ac tormentis usque ad summum periculum afflictum; Gemine carissime, velim audias eum, et si compereris haec ita admissa, rem severe exequaris. " 
escritura, con la finalidad de la mujer que ha perdido su virginidad pueda contraer un matrimonio honesto. Pero si el opresor y violador de la ingenua virgen no cuenta con un patrimonio aceptable o no es un noble, sufrirá el máximo castigo.

En este fragmento se tratan diferentes supuestos para los que también se establece diferente sanción, por lo que vamos a analizar cada uno de ellos.

El primer caso tratado es el del noble, no casado y que además tiene cierto patrimonio, en cuyo caso, además de obligarle a contraer nupcias con la mujer, se establece una sanción patrimonial, puesto que se le condenará a dotar a la misma con una quinta parte de su patrimonio.

En segundo lugar, se distingue si el mismo noble con patrimonio estaba casado, en cuyo caso éste estará obligado a entregar una tercera parte de su patrimonio a la corrompida, en idónea y solemne escritura, con la finalidad de que la mujer que ha perdido su virginidad pueda contraer un matrimonio honesto.

En tercero y último lugar se prevé el supuesto de que el violador ni sea noble ni tenga patrimonio, en cuyo caso la pena que se le aplicará será el máximo castigo, es decir, la muerte, aunque no se especifique de qué manera se aplicará ésta.

De la distinción de estos supuestos podemos extraer algunas conclusiones:

- La diferente sanción penal según la condición social y la disponibilidad patrimonial del violador, puesto que el noble con patrimonio puede conservar su vida, mientras que no puede hacerlo, en ningún caso, aquel que no lo es. Parece que el legislador prima la posibilidad de que la mujer obtenga una compensación patrimonial que le pueda, además, ofrecer la posibilidad de evitar el perjuicio que le puede suponer el hecho de haber perdido su virginidad a la hora de poder contraer matrimonio. No podemos olvidar la importancia que tiene en esta época la virginidad de la mujer, puesto que ello va a afectar, de forma determinante, sus posibilidades de contraer matrimonio, afectando ello, no sólo a ella, sino también, de nuevo, al honor, e incluso al patrimonio, de su familia.

- En el caso del noble con patrimonio, también se distingue el caso de que éste esté casado o no. En el primer caso, la reparación es puramente patrimonial, pero en el segundo, además de la obligación de dotarla con una parte de su patrimonio, deberá contraer matrimonio con ella.

- Otra cuestión relevante es el hecho de que en el caso de la reparación patrimonial en el supuesto del noble con patrimonio y casado, se obliga a éste a formalizar la entrega de una tercera parte de su patrimonio en documento escrito (solemni scriptura), exigencia ésta que no aparece en el caso del noble no casado, puesto que en este caso el patrimonio que se entrega a la mujer se hace en concepto de dote, lo cual supone que se trata de un patrimonio destinado al sostenimiento de las cargas matrimoniales pero que va a gestionar el marido, si bien es cierto que, en caso de divorcio, dichos bienes siguen a la mujer.

También se regula en el Edicto el caso de la violación de virgen ingenua cuando el sujeto activo es un esclavo, tal y como vemos al analizar el contenido del siguiente fragmento. 


\begin{abstract}
63. Si servus alienus aut originarius ingenuam virginem per vim corruperit.

Si servus alienus aut originarius ingenuam virginem per vim corruperit, aut stuprum viduae per vim intulerit, convento domino, rebus discussis atque patefactis, capite feriatur ${ }^{69}$.
\end{abstract}

En este caso se nos dice que si el siervo, ajeno u originario, por violencia ha corrompido a una virgen ingenua, o por la fuerza ha inferido estupro a la viuda, con acuerdo del dueño, discutidas y claras las cosas, sea condenado a muerte.

El fragmento regula la situación en la que un dueño acuerda con el siervo o el colono que cometa violación sobre una virgen e ingenua, o estupro por la fuerza a una viuda. De la lectura del texto podemos concluir que hay un acuerdo o un mandato; es decir, el siervo o colono actúa a petición o de acuerdo con el dueño, aunque ello no va a suponer castigo alguno para este último, a pesar de que parece ser el inductor del acto delictivo. El fragmento tiene en cuenta la condición social de la mujer y distingue si se trata de una virgen ingenua o una viuda, aunque, en todo caso, se impone la pena de muerte.

Tanto el caso de la virgen ingenua como el de la viuda honesta, son tratados de igual manera, puesto que lo que tienen en común es que se trata de mujeres no casadas que sufren una agresión sexual no consentida y la sanción al autor del delito también va a ser la misma, la pena de muerte. Nos resulta llamativo que se haga tal diferenciación para luego darles el mismo tratamiento ${ }^{70}$. Nosotros pensamos que, tal vez, el legislador al redactar el fragmento tenga en mente el concepto de estupro que los juristas irán perfilando a partir de la promulgación de la lex Iulia de adulteriis ${ }^{71}$, en contraposición al de adulterio, de manera que aquél se refiere a la unión carnal con mujer no casada, término que incluiría a la mujer viuda o núbil, o mujer con niños y este último se refiere a la unión carnal con mujer casada. Quizá por ello, al referirse al caso de la viuda se utiliza el término estupro, cuando lo que se sanciona es una violación, puesto que se trata de una relación sexual forzada.

Al caso de la violación de viuda, sea cual sea la condición del sujeto activo se refiere:

Fr.60. Si quis viduae violenter stuprum intulerit.

Si quis viduae stuprum violenter intulerit, cuiuslibet loci corruptor adulterii poena depereat.

El fragmento afirma que si alguien cometiera estupro con violencia contra una viuda que no consiente, cualquiera que sea el rango del corruptor perecerá por la pena de adulterio, que no es otra que la pena de muerte.

\footnotetext{
${ }^{69}$ Lo expuesto aquí sobre este texto aparece ya en nuestro trabajo "La situación..." cit., pág. 12

${ }^{70}$ GEOFFREY, N., The family...cit., pág. 127, señala al tratar la legislación de Constantino sobre el matrimonio de las viudas, cómo con frecuencia se trata de forma conjunta la situación de las vírgenes y las viudas, entendiendo que la razón para ello sería el especial respeto que ambas merecen.

${ }^{71}$ AA. VV. (RODRÍGUEZ LÓPEZ, R., BRAVO BOSCH, M.J.), Mujer: algunas historias e instituciones de derecho romano, (Madrid, 2013), VALMAÑA-OCHAÍTA, A., "La mujer romana en las relaciones de pareja”, págs. 135 y ss.
} 
Curiosamente, después de haber acotado el delito de estupro romano como el yacimiento con consentimiento con mujer viuda o virgen o un muchacho joven, nos encontramos con que el fragmento del cuerpo teodoriciano en el que se regula el estupro se habla de un estupro con viuda y mediando la violencia, por lo que debemos entender que el delito que se está sancionando es el de violación ${ }^{72}$, siguiendo en ello, una vez más, la tradición romana, en la que no se perfila jurídicamente el delito de violación, pues cuando regula tal delito habla siempre de estupro con violencia.

El fragmento 64 regula los casos de violación en los que el autor es un colono y en los que la víctima es una colona.

\section{Si quis ancillam alienam aut originariam virginem corruperit.}

Ancillam alienam virginem vel originariam cuiuslibet aetatis, quisquis ingenuus, nulli tamen quolibet modo obnoxius civitati, corruperit, si dominus voluerit, aut corruptor ipse rogaverit, et apud gesta professus fuerit, mansurus in domini mulieris potestate, eius quam vitiavit contubernium non relinquat, nec, eadem mortua, discedendi habeat facultatem. Quod si dominus ancillae non consenserit, aut ille profiteri noluerit, tunc aut huius meriti duo mancipia domino tradat, eius iuri profutura, si eius substantia patiatur: aut si hoc implere non potuerit, caesus districtissime fustibus vicinae civitatis collegio deputetur: quod iudex eiusdem loci, periculi sui memor, implere et custodire debebit ${ }^{73}$.

En la primera parte del fragmento se nos dice que un ingenuo que no ocupa cargo vinculante de la ciudad, que hubiera violado a una esclava o una originaria ajena, si lo exige el dueño o el mismo lo reclama en solemne declaración en los archivos públicos, debe vivir en contubernio con la mujer bajo la potestad del dominus, bajo la cual permanecerá incluso después de la muerte de la mujer.

En la segunda parte, se ocupa del supuesto en el que el propietario de la esclava no consiente o el corruptor no quiere hacer la declaración. En este caso, quedará obligado a entregar dos esclavos de igual valor y el resarcimiento de las posibles pérdidas financieras ocasionadas al dueño. En el caso de que no tenga capacidad económica para hacer frente a esta obligación, después de haber sido fustigado, será juzgado por un tribunal de magistrados de la ciudad más cercana, el juez de cuyo lugar ha debido cumplir y custodiar teniendo presente el escrito.

Este es uno de los supuestos en los que el legislador ostrogodo no se limita a transcribir la norma romana, ${ }^{74}$ sino que la manipula con la intención de adaptarla a sus propias

\footnotetext{
${ }^{72}$ Esta referencia al estupro con violencia la encontramos también en otro texto de Marciano, en el que establece la pena capital como castigo fijado por la lex Iulia de vis publica para el delito de violación a hombre joven, mujer u otro cualquiera, D. 48, 6, 4: Praeterea punitur huius legis poena, qui puerum, vel femianm, vel quemquam per vim stupraverit.

${ }^{73} \mathrm{El}$ análisis de este fragmento coincide con el que ya hicimos del mismo en el trabajo anterior sobre la situación del colono en el Edicto de Teodorico, "La situación..." pág. 13.

${ }^{74}$ En este caso una constitución del emperador Valentiniano del año 451 que encontramos en Nov. Val. 31.5: Advenae plerumque tenues abiectaeque fortunae quorundam se obsequiis iungunt, ut, simulata laboris et obsequiorum patientia, accepto sumptu ac vestitu inluviem et squalorem egestatis evadant. Ubi
} 
necesidades. Una clara manifestación de ello es la referencia al ingenuo que aparece en el fragmento, ya que en el texto de la constitución romana de la que toma la regulación no aparece la mención al ingenuus, sólo la del colono huido. ${ }^{75}$

En este caso se establece el castigo corporal más una remuneración en especie, siendo esta última una idea ajena al derecho romano. Por otra parte, vemos que la sanción no es la misma que la del caso regulado en el supuesto anterior, en el que la víctima era una ingenua, pues en este el castigo era la pena de muerte. Así pues, se mantiene la tradicional distinción de clases y, por tanto, una sanción diferenciada para cada caso, así como también el tratamiento conjunto de esclavos y colonos, que es bastante habitual en el Código de Teodorico.

\section{ADULTERIO}

La comisión de un delito de adulterio exige, por su naturaleza, mantener relaciones sexuales con una mujer casada con otro.

A la regulación del adulterio, el Edicto, sólo dedica dos fragmentos, en los que básicamente se insite en la confirmación de la pena capital para adúlteros y adúlteras, así como para los cómplices en la comisión de tal delito.

El primer fragmento que se ocupa de tal delito es:

\section{Fr. 38. De adultero et adultera.}

Adulteri et adulterae, intra iudicia convicti, interitum non evadant, ministris eiusdem criminis aut consciis pariter puniendis.

En el texto se nos dice que adúlteros y adúlteras, sometidos a juicio, no se evadirán de una muerte violenta; los cómplices o conocedores del adulterio sufrirán la misma pena.

La gravedad de la pena deviene del hecho de que el adulterio, a partir de la promulgación de la Lex Iulia de adulteriis coercendis de Augusto,es una ofensa pública que atenta contra el orden social, ${ }^{76}$ lo cual supondrá que, partir de este momento, el

de angustiis cladis suae et humanitate et miseratione colligentes fuerint liberati, iam repleti, iam nihil de miseria cogitantes eligunt feminas ad patremfamilias pertinentes, solertia forma utilitate meliores; cum satias ceperit, derelinquunt: non statu priore perpenso, non adsuetudine coniunctionis, non dulcedine filiorum, nulla lege prohibente discedunt. Itaque si nulli quolibet modo obnoxius civitati ad praedium se cuiuscumque rusticum urbanumque collegerit et mulieri obnoxiae sociari voluerit, gestis municipalibus profiteatur habitandi ubi elegerit voluntatem, ut hoc vinculo praecedente nec habitaculum quod placuit deserat nec consortium mulieris abrumpat: qua professione deprompta salva ingenuitate licentiam non habeat recedendi.

75 SCHIPP, O., Der weströmische Kolonat von Konstantin bis zu den Karolingen (332 bis 861), (Hamburgo, 2009), pág. 295.

${ }^{76}$ BAUMAN, R.; Crime and Punishment in Ancient Rome, (New York, 1996), pág. 24: “Augustus broke new ground with the Lex Iulia de adulteriis coercendis which established a public jury-court for offences against morality that had possibly been the exclusive preserve of family courts until then". RODRÍGUEZ 
adulterio tenga la consideración de delito público. Con la sanción penal del adulterio no se sanciona toda relación extramatrimonial, sino sólo aquellas que se mantienen con mujer casada en justas nupcias ${ }^{77}$, pues lo que se persigue es proteger el honor de la familia, sobre todo de la mujer, pero también el propio linaje de la misma, que puede verse alterado por el comportamiento de la mujer adúltera. En cuanto a la pena, la lex Iulia imponía, con carácter general, penas que suponían una limitación a la libertad de los condenados y éstas consistían en el exilio y la pérdida de parte de su patrimonio ${ }^{78}$, si bien hay que tener encuenta que, en el caso de las mujeres esta pérdida de parte de su patrimonio sólo podría hacerse efectiva en el caso de que fuera una sui iuris.Especial mención merece la regulación que del ius occidendi del padre y el marido de la adúltera hace la lex Iulia, para ello hay que señalar que en la época anterior a dicha ley, el adulterio era un delito cuya sanción quedaba restringida al ámbito de la familia, y ello suponía que tanto el padre como el marido eran titulares del llamado ius occidendi, que les permitía matar a los adúlteros. La lex Iulia va a regular el ejercicio de este derecho, de manera que lo mantiene en el caso del padre, quien tiene el derecho a ejercerlo, pero no está obligado a ello y, en todo caso, la ley exige que se cumplan tres requisitos: que la hija esté sometida a su potestas o estando bajo la de su marido, dicho matrimonio cum manu se hubiera contraído con la autorización del padre en la conventio, que el padre haya sorprendido a los adúlteros in fraganti, es decir, durante la comisión del adulterio, y, por último, que mate a los dos adúlteros y en el mismo momento ${ }^{79}$, pues en caso de que el padre sólo mate a uno de los dos será acusado de homicidio. En el caso del marido de la adúltera, la lex Iulia mantiene el ius occidendi para éste, pero sólo en el caso de que dé muerte al cómplice del adulterio de su mujer, y no a ésta, y que al igual que en el caso del padre, haya sorprendido a los adúlteros en el momento de la comisión del delito ${ }^{80}$. Este diferentetratamiento, esconsecuencia del propio fundamento de ambos derechos, puesto que en el caso del padre, está ejerciendo un poder que tiene como pater familias, que elimina la antijuridicidad de la muerte de los adúlteros, mientras que en el caso de la muerte del adúltero por parte del marido de la adúltera, "el hecho

ARROCHA, B., "La concepción jurídica y moral del adulterio en Roma: fuentes para su estudio", Anales de la Facultad de Derecho. Universidad de La Laguna, 27, 2010, pág. 128.

${ }^{77}$ En este sentido podemos ver una constitución de los emperadores Severo y Antonino del año 197, en C. 9, 9, 1: Publico iudicio non habere mulieres adulterii accusationem, quamvis de matrimonio suo violato queri velint, lex Iulia declarat, quae, cum masculis iure mariti facultatem accusandi detulisset, non idem feminis privilegium detulit.

${ }^{78}$ Paul. Sent. 2, 26, 14: adulterii convictas mulieres dimidia parte dotis et tertia parte bonorum ac relegatione in insulam placuit coerceri; adulteris vero viris pari in insulam relegatione dimidiam bonorum partem auferri, dummodo in diversas insulas relegentur.

${ }^{79}$ PANERO ORIA, P.; Ius occidendi et ius accusandi en la Lex Iulia de Adulteriis coercendis, (Valencia, 2001), págs. 129 y ss.

${ }^{80}$ D. 48, 5, 24, pr.: Marito quoque adulterum uxoris suae occidere permittitur; sed non quemlibet, ut patri; nam hac lege cavetur, ut liceat viro deprehensum domi suae, non etiam soceri, in adulterio uxoris occidere eum, qui leno fuerit, quive artem ludicram ante fecerit, in scenam saltandi cantandive causa prodierit, iudiciove publico-damnatus, neque in integrum restitutus erit, quive libertus eius mariti, uxorisve patris, matris, filii, filiae, utrius eorum fuerit, nec interest, proprius cuius eorum, an cum alio communis fuerit, -nec interest, proprius cuius eorum, an cum alio communis fuerit-, quive servus erit. 
cometido es un delito -homicidio-, si bien, existe una causa de exclusión de la pena (su particular estado de ánimo) que hace que no sea perseguible". ${ }^{81}$

Vemos pues, cómo esta posibilidad de dar muerte a los adúlteros está limitada al ejercicio del ius occidendi, que sólo correspondeal marido y al padre de la adúltera, y sujeto al cumplimiento de determinadas condiciones, pues fuera de este ámbito no se contempla tal pena. Fuera de estos supuestos, las penas establecidas por la legislación augusteas eran: el exilio en una isla ${ }^{82}$ y la confiscación de parte de las propiedades de los adúlteros; en el caso de la mujer, la mitad de su dote y la tercera parte de sus propiedades, y en el caso del hombre, la mitad de sus propiedades. ${ }^{83}$

Esta sería la regulación, en cuanto a la pena, que se mantendría durante los siglos posteriores, hasta que, por ser un comportamiento que ataca a la propia sociedad romana, unido, probablemente, a la influencia de las ideas cristianas, lleva a que en época de Constantino, se castigue con la máxima sanción: la pena de muerte; así se desprende de una constitución del año 314 que incluye el adulterio en la lista de delitos que llevan aparejado dicho castigo ${ }^{84}$. Siendo este castigo el que conserva el legislador del Edicto de Teodorico, por lo que lo incluye en el fragmento 38, probablemente con la intención de reafirmarse en su mantenimiento.

Tras haber confirmado la regla de la aplicación de la misma pena a adúlteros y cómplices, en el fragmento siguiente del Edicto, se hace referencia a dos supuestos concretos de cómplices, como pasamos a ver.

\section{Qui, ut adulterum fuerit (fieret), domum preaestiterit.}

Qui ut adulterium fieret, domum vel casam praebuit; quive mulieri, ut adulterio consentiret, suasit, capite puniatur

Cualquiera que ofrece casa a los que cometen adulterio o cualquiera que convence a la mujer para que cometa adulterio sufrirá la pena capital.

Esta referencia a aquel que cede su casa para facilitar la comisión del delito de adulterio es una forma de complicidad que ya los juristas romanos interpretaban de forma amplia, entendiendo el término casa como cualquier lugar que se presta para tal fin. ${ }^{85}$

\footnotetext{
${ }^{81}$ PANERO ORIA, P., Ius...cit., pág. 165, n. 167

${ }^{82}$ Paul. Sent. 2, 26, 14: Adulterii convictas mulieres dimidia parte dotis et tertia parte bonorum ac relegatione in insulam placuit coerceri: adulteris vero viris pari in insulam relegatione dimidiam bonorum partem auferri, dummodo in diversas insulas relegentur.

${ }^{83}$ EVANS GRUBBS, J., Women and the law in the Roman Empire, (Oxford, 2002), pág. 84.

${ }^{84}$ C. Th. 9, 40, 1: Imp. Constantinus a. ad Catulinum. Qui sententiam laturus est, temperamentum hoc teneat, ut non prius capitalem in quempiam promat severamque sententiam, quam in adulterii vel homicidii vel maleficii crimine aut sua confessione aut certe omnium, qui tormentis vel interrogationibus fuerint dediti, in unum conspirantem concordantemque rei finem convictus sit et sic in obiecto flagitio deprehensus, ut vix etiam ipse ea, quae commiserit, negare sufficiat. Dat. III. non. nov. Treviris. acc. XV. kal. mai. Hadrumeti, Volusiano et Anniano coss.

${ }^{85}$ FERRINI, C., Derecho penal romano. Trad. de PÉREZ ALONSO, R., ROZAS ÁLVARO, A., SAN JUAN SECCHIUTTI, S., TIRADO PABLOS, M., (Barcelona, 2017), pág. 340, donde en nota 51 el autor cita alguno de estos textos, como son: D. 48,5, 9 (Marcianus libro secundo de adulteriis):pr. Qui domum
} 
Con relación a este tipo de complicidad nos parece interesante detenernos en el contenido del siguiente texto de Papiniano:

D. 48, 5, 8, pr. (Pap. Lib. 11 de adulteriis): Qui domum suam, ut stuprum adulteriumve cum aliena matre familias, vel cum masculo fieret, sciens praebuerit, vel quaestum ex adulterio uxoris suae fecerit, cuiuscumque sit conditionis, quasi adulter punitur.

En este caso, Papiniano nos dice que el que a sabiendas hubiere facilitado su casa, para que se cometiera estupro o adulterio con una madre de familia, que era de otro, o con un varón, o realizare ganancia con el adulterio de su propia mujer, es castigado, de cualquier condición que sea, como adúltero. Parece claro que el fragmento teodoriciano hace referencia al mismo supuesto y establece la misma regulación, pero hay algún elemento que no aparece en los dos textos y que, en nuestra opinión, merece nuestra atención.

- En el texto del jurista romano encontramos, de nuevo, la referencia conjunta a adulterio y estupro.

- En el texto de Papiniano no se utiliza el término mulier, sino la expresión matre familias: Sobre el significado de dicha expresión, podemos acudir a la explicación que encontramos en un texto de Papiniano ${ }^{86}$, en la que se nos dice que en este concepto se incluye no sólo a la mujer casada, sino también a la viuda. Con esta expresión se quiere señalar a un grupo concreto de mujeres, que son aquellas que representan el concepto romano de matrona, como mujer ejemplo de castidad y de las buenas costumbres romanas, frente a aquellas mujeres a las que no se les supone un comportamiento tal, como sería el caso de la meretrix, la ancilla y la concubina. ${ }^{87}$

No encontramos en el fragmento del Edicto de Teodorico la referencia al supuesto de aquel que obtiene un beneficio con el adulterio de su propia mujer, aunque podría incluirse dentro del supuesto que sí contempla, de aquel que convence a la mujer para

\footnotetext{
suam, ut stuprum adulteriumve cum aliena matre familias vel cum masculo fieret, sciens praebuerit vel quaestum ex adulterio uxoris suae fecerit: cuiuscumque sit condicionis, quasi adulter punitur.1. Appellatione domus habitationem quoque significari palam est. D. 48, 5, 10 (Ulpianus libro quarto de adulteriis): pr. Et si amici quis domum praebuisset, tenetur.1. Sed et si quis in agro balneove stuprum fieri praebuisset, comprehendi debet.2. Sed et si in domum aliquam soliti fuerint convenire ad tractandum de adulterio, etsi eo loci nihil fuerit admissum, verum tamen videtur is domum suam, ut stuprum adulteriumve committeretur, praebuisse, quia sine colloquio illo adulterium non committeretur. D. 48, 5, 11,1 (Papinianus libro secundo de adulteriis): Mulieres quoque hoc capite legis, quod domum praebuerunt vel pro comperto stupro aliquid acceperunt, tenentur. D. 48, 5, 33.1 (Macer libro primo de publicis iudicis): Cum alterum ex adulteris elegerit maritus, alterum non ante accusare potest, quam prius iudicium finietur, quia duos simul ab eodem accusari non licet. Non tamen prohibetur accusator simul cum adultero vel adultera eum quoque accusare, qui domum suam praebuit vel consilio fuit, ut crimen redimeretur.

${ }^{86}$ D. 48, 5, 10, pr. (Pap. lib. sec. de adulteriis): Mater autem familias significatur non tantum nupta, sed etiam vidua.

${ }^{87}$ DIXON, J. E.; The Language...cit., pág. 23.
} 
que consienta en el adulterio, aunque sin precisar que se trate de su marido ni de que ello se haga para obtener algún beneficio económico.

Todo ello, nos hace pensar en un legislador que, en esencia, mantiene la legislación romana sobre el adulterio, por lo que sólo ve la necesidad de dedicar dos cortos fragmentos al tema de la pena, en el sentido de confirmar la pena capital ya establecida por Constantino y el tratamiento a los cómplices.

\section{CONCLUSIONES.}

Partimos, en nuestra investigación, de la premisa de que el Edicto de Teodorico es un cuerpo legislativo promulgado para ser aplicado en el territorio del imperio ostrogodo del siglo VI. Ello nos da la perspectiva histórica que tan necesaria es para interpretar cualquier norma jurídica.

Se trata de un breve cuerpo jurídico que no pretende regular todos y cada uno de los conflictos, sino, probablemente, aquellos que por las circunstancias del momento son más importantes o que requieren de una nueva regulación diferente, total o parcialmente, a la ya existente, que, en la mayoría de los casos, es la romana, todavía vigente en ese territorio.

A pesar de ser un cuerpo legal bastante reducido, llama la atención que se ocupe de algunos aspectos de los delitos de rapto, estupro, con y sin violencia, es decir, violación, y adulterio, lo cual no puede ser más que una consecuencia de la importancia que para la sociedad del momento representan tales delitos. Como hemos visto a lo largo del trabajo, dicha importancia deriva del bien jurídico a proteger en estos casos, que incluye tanto el honor y la integridad física de la mujer, como el honor de la familia a la que pertenece.

Sobre el rapto, es clara la influencia de la regulación constantinianade la figura, sobre todo en la dureza de las penas, aunque el legislador, como hemos visto, no duda en apartarse de ella cuando así lo considera oportuno, por ejemplo al introducir la regulación específica del rapto de colona o del rapto en el que interviene el colono. Ello como consecuencia de la importancia que dicha figura tiene en un ámbito básicamente rural, en el que la mano de obra es vital para la explotación de la tierra.

Al igual que ocurre en la regulación romana, el estupro es un delito que se comete al tener relaciones sexuales consentidascon una persona con la que no se pueden tener atendiendo a la especial consideración social de la misma. Tampoco en la regulación teodoriciana el delito de violación merece una consideración individualizada, puesto que se concibe como el estupro en el que no hay consentimiento y media, por tanto, violencia. Vemos cómo el legislador se detiene en regular algunas cuestiones sobre todo con relación al caso de la viuda, cuya consideración debería ser especialmente relevante en el entorno social del momento, lo cual conllevaría la exigencia de una especial rectitud en el comportamiento de la misma. Así, se especifican determinados 
comportamientos de la viuda que la califican como "mujer vulgar", y que, por lo tanto, la dejan fuera del tipo penal del estupro.

Siguiendo su antecedente romano, también el legislador ostrogodo trata la violación dentro del estupro con violencia, estableciendo penas de carácter patrimonial que intentan paliar el mayor perjuicio que, a sus ojos, supone para la mujer sufrir una agresión de dicho tipo, y que no es otra que el obstáculo que, con toda seguridad, ello va a suponer en la consecución de uno de los principales objetivos de su familia, conseguir un matrimonio honorable y ventajoso económicamente.

A la regulación del adulterio dedica el Edicto muy poca atención y solo para confirmar la pena de muerte de adúlteros y cómplices, cuyo origen encontramos en la legislación constantiniana, y una referencia expresa a algunos tipos de cómplices. En nuestra opinión ello supone el mantenimiento de la vigencia de la regulación romana sobre el adulterio, ya que el bien jurídico a proteger sigue siendo el mismo, la honorabilidad de la familia y al mismo tiempo el propio linaje de la misma, que puede verse alterado por las relaciones adúlteras de la mujer.

\section{BIBLIOGRAFÍA}

AMORY, P., People and identity in Ostrogothic Italy, (Cambridge, 1997)

BARNWELL, P., "Emperors, Jurists and Kings: Law and Custom in the Late roman and Early Medieval west", Past and Present a journal of historical studies, 168, 2000.

BAUMAN, R.; Crime and Punishment in Ancient Rome, (New York, 1996)

BERNAD SEGARRA, L., "La situación jurídica del colonus en el Edicto de Teodorico", Revista General de Derecho Romano, 29, 2017.

COLLINET, P., "Le colonat dans l'empire romain", en Recueils de la Societé Jean Bodin, 2, (Bruxelles, 1959)

CUENA, F., "Nuevos significados de origo en las fuentes legislativas postclásicas", Revista General de Derecho Romano, 10, 2008.

DE MARTINO, F., Historia económica de la antigua Roma, (Trad. E. Benitez, Storia economica di Roma antica), (Madrid, 1985)

DESANTI, L., "Costantino, Il ratto e il matrimonio riparatore”, SDHI, 52, 1986.

DIXON, J. E.; The Language of Roman Adultery. Tesis doctoral. University of Manchester, 2012.

EIBACH, D., Untersuchen zum spätantiken Kolonat in der kaiserlichen Gesetzgebung, (Bonn, 1980)

EVANS GRUBBS, J., "Abduction marriage in antiquity: A Law of Constantine (CTh IX.24.I) and Its Social Context”. The Journal of Roman Studies, vol. 79,1989.

FERNÁNDEZ DE BUJÁN, A, en Derecho Romano,(Madrid, 2017) 
FERNÁNDEZ DE BUJÁN, A., "Reformas legislativas de Augusto", Revista General de derecho romano, 23, 2014.

FERNÁNDEZ DE BUJÁN, A., Derecho Público Romano, 20ª ed., (Madrid, 2017)

FERRINI, C., Derecho penal romano. Trad. de PÉREZ ALONSO, R., ROZAS ÁLVARO, A., SAN JUAN SECCHIUTTI, S., TIRADO PABLOS, M., (Barcelona, 2017)

GEOFFREY, N., The family in late antiquity: The rise of christianity and the endurance of tradition, (Leiden, Boston 2002)

GIRARD, P.F., "Les leges Iuliae iudiciorum publicorum et privatorum”, ZSS, 34, 1923.

GREY, C., "Landowning and Labour in the Rural Economy", AA. VV. (ARNOLD, J., BJORNLIE, S., SESSA, K.), A Companion to Ostrogothic Italy, (Leiden, 2016)

HEATHER, P., "Gens and regnum among ostrogoths", pags. 107 y ss.; AA. VV. (Ed. GOETZ, JARNUT, POHL), Regna and Gentes. The relationship between late Antique and early medieval peoples and kingdoms in the transformation of the roman world, (Leiden, 2003)

HEATHER, P., Goths and romans, (Oxford, 1991)

HERREROS GONZÁLEZ, C.; "Las meretrices romanas: mujeres libres sin derechos", Iberia. Revista de la Antigüedad, 14, 2001.

K. E., Deutsch-Lateinisches Handworterbuch aus den quellen zusammengetragen und mit besonderes Bezugnahme auf Synonymik und Antiquitäten, mit Berücksichtigung der besten hulfsmittel, (Leipzig, 1961)

LAFFERTY, S. Law and Society in the Age of Theodoric the great. A Study of the Edictum Theoderici,(Cambridge, 2013)

LECCE, M., "La vita económica de 1'Italia durante la dominazione dei goti nelle varie de Cassiodoro", Economia e Storia, 3, 1956.

LEWIS- SHORT, A Latin Dictionary, (Oxford, 1879)

NGUYEN, N. L., "Roman rape: an overview of roman rape laws from the republican period to Justinian's reign", Michigan Journal of Gender and Law. Vol. 13, 1, 2006.

PANERO ORIA, P.; Ius occidendi et ius accusandi en la Lex Iulia de Adulteriis coercendis, (Valencia, 2001)

PASTOR DE AROZENA, B., "Retórica imperial: el rapto en la legislación de Constantino", Faventia, 20/1, 1998.

PATETTA, F., Sull'Anno della promulgacione dell'Editto di Teodorico, (Torino, 1893)

PULIATTI, S., "La dicotomía vir-mulier e la disciplina del ratto nelle fonti legislative tardo-imperiali”, SDHI, 61, 1995.

QUERZOLI, S. "La puella rapta: paradigmi retorici e apprendimento del diritto nelle Istituzioni di Elio Marciano", Annali Online Lettere, vol. 1-2, 2011. 
RASI, P. "Ancora sulla paternità del Edictum Theodorici”, Annali di storia dil diritto 5/6, 1961-1962.

RODRÍGUEZ ARROCHA, B., "La concepción jurídica y moral del adulterio en Roma: fuentes para su estudio", Anales de la Facultad de Derecho. Universidad de La Laguna, 27, 2010.

RODRÍGUEZ ORTIZ, V. en Historia de la violación. Su regulación jurídica hasta fines de la edad media, (Madrid, 1997)

SCHIPP, O., Der weströmische Kolonat von Konstantin bis zu den Karolingen (332 bis 861), (Hamburgo, 2009)

VALMAÑA-OCHAÍTA, A., "La mujer romana en las relaciones de pareja” AA. VV. (RODRÍGUEZ LÓPEZ, R., BRAVO BOSCH, M.J.), Mujer: algunas historias $e$ instituciones de derecho romano, (Madrid, 2013)

VISMARA, G.," Edictum Theodorici”, Scritti di storia giuridica 1, Milano, 1987.

VOLTERRA, E., "Intorno alla prescrizione dei reati in diritto romano", BIDR, 37, 1929. 